\title{
DE LA MERA VOLUNTAD A LA GARANTÍA DEL DERECHO: LAS MUJERES EN LOS PARLAMENTOS AUTONÓMICOS ${ }^{1}$
}

\author{
FROM THE MERE WILL TO THE GUARANTEE OF THE LAW: WOMEN IN \\ AUTONOMOUS PARLIAMENTS
}

\author{
Julia Sevilla Merino \\ Universitat de València
}

Cómo citar / Nola aipatu: Sevilla Merino, J. (2021). De la mera voluntad a la garantía del Derecho: las mujeres en los parlamentos autonómicos. Legebiltzarreko Aldizkaria - LEGAL - Revista del Parlamento Vasco, 2: 90 -135

https://doi.org/10.47984/legal.2021.004

\section{RESUMEN}

La reciente celebración de los 40 años del Parlamento Vasco el pasado año es una ocasión excelente para reflexionar sobre cómo ha evolucionado la imagen de las cámaras parlamentarias, qué ha ocurrido durante esos años para que, entre otras cosas, se haya pasado de una presencia casi testimonial de diputadas a que más del $50 \%$ de los escaños estén ocupados por mujeres. Ha sido un fenómeno expansivo: Cortes Generales, cámaras autonómicas, parlamentos de los países de nuestro entorno, aunque con repercusiones diferentes, y organismos representativos de la ciudadanía o de los Estados. Para ello veremos cómo han influido algunos factores ajenos a la vida parlamentaria: organismos internacionales que actúan en defensa de los derechos, reformas constitucionales en los países de nuestro entorno geográfico, científicas y asociaciones de mujeres en la academia y fuera de ella como el movimiento feminista. La respuesta, como corresponde a la institución legislativa en un Estado de derecho, ha sido la aprobación de leyes que garanticen la igualdad en la titularidad de un derecho, aunque haya sido necesario el recurso a la justicia. El resultado es que la imagen de nuestros parlamentos se parece cada vez más a la sociedad a la que representan.

1 Quiero agradecer al Parlamento Vasco que se haya acordado de mí para que participe en este segundo número de la revista LEGAL. La elaboración de este artículo en tiempo de pandemia, por otra parte, ha hecho que haya tenido que "molestar" a contactos personales para la obtención de datos y bibliografía: Amparo Caus, bibliotecaria de Les Corts, a Isabel García Caluo, funcionaria del Instituto de la Mujer, a Mar Esquembre, compañera de la Red con la que he compartido las inquietudes del proceso creativo, y a Jaume Molins, con el que siempre he trabajado en mi época de letrada, autor de las estadísticas de las Corts Valencianes y que me ha prestado sus habilidades para que este texto se acople a los requisitos de edición. 


\section{PALABRAS CLAVE}

Derechos, democracia, igualdad, participación política, paridad, perspectiva de género, parlamentos autonómicos, leyes de igualdad.

\begin{abstract}
Celebrating the 40th anniversary of the Basque Parliament is an excellent occasion to reflect about the events that have taken place during these past years in parliamentary life. Among other things, the quasi-symbolic presence of female members of parliament has increased more than half of the seats. This phenomenon is not exceptional: the same has happened in the Spanish Parliament, in our regional parliaments, in the parliaments of neighbouring countries and in any other agency or entity representing the citizens or the State. We will analyse how certain factors alien to parliamentary life have influenced this process, such as the advocacy of international agencies, some constitutional reforms in other countries, the work of female scientists and women's associations, both in academia and outside, as well as the feminist movement. The State has responded in a manner suitable to the rule of law, i.e. by passing legislation that ensures equal rights although sometimes recourse to justice has been necessary. The outcome is that the image projected by our parliaments is increasingly similar to the society they represent.
\end{abstract}

\section{KEYWORDS}

Rights, democracy, equality, political participation, parity, gender perspective, autonomic parliaments, equality laws.

\section{LABURPENA}

Eusko Legebiltzarraren 40. urteurrena ospatzea, joan den urtean, aukera bikaina da hausnartzeko zer-nolako bilakaera izan duen Ganbera parlamentarioen irudiak, zer gertatu den urte horietan emakumezko diputatuen presentzia hutsaren hurrengoa izatetik eserlekuen \% 50a baino gehiago emakumezkoek betetzera pasatzeko, besteak beste. Fenomeno hedakorra izan da: Gorte Nagusiak, ganbera autonomikoak, inguruan ditugun herrialdeetako parlamentuak, nahiz eta ondorio desberdinekin, eta herritarren edo Estatuen ordezkaritzarako organismoak. Horretarako, aztertuko dugu zer-nolako eragina izan duten bizitza parlamentariotik at dauden zenbait faktorek: eskubideen defentsan diharduten nazioarteko erakundeak, konstituzio-erreformak gure inguru geografikoko herrialdeetan, emakumezko zientzialariak eta emakumeen elkarteak, bai akademia barruan, bai kanpoan, hala nola mugimendu feminista. Erantzuna, Zuzenbide Estatu batean instituzio legegileari dagokion bezala, eskubide baten titulartasunean berdintasuna bermatzen duten legeak onestea izan da, nahiz eta beharrezkoa izan den justiziara jotzea. Emaitza da gure parlamentuen irudiak gero eta antz handiagoa duela ordezkatzen duten gizartearena.

\section{GAKO-HITZAK}

Eskubideak, demokrazia, berdintasuna, parte-hartze politikoa, parekotasuna, genero-ikuspegia, legebiltzar autonomikoak, berdintasun-legeak.

\section{SUMARIO}

I. INTRODUCCIÓN.

II. LA PARTICIPACIÓN POLÍTICA DE LAS MUJERES: CORTES GENERALES Y PARLAMENTOS AUTONÓMICOS.

III. MUJERES Y POLÍTICA.

IV. EL CAMINO A LA PARIDAD.

V. PROPUESTAS DE LAS COMUNIDADES AUTÓNOMAS. 1. Ley Orgánica 3/2007, de 22 de marzo, para la igualdad efectiva de mujeres $y$ hombres (LOI).

VI. CONCLUSIÓN. BIBLIOGRAFÍA. ANEXO. 


\section{INTRODUCCIÓN}

El derecho a la ciudadanía de las mujeres no es una historia sencilla. Es hablar de una historia paralela, casi de una vida subterránea ${ }^{2}$ e incongruente, mientras el mundo visible evolucionaba. Se sucedían avances en la ciencia que mejoraban la vida de la población, se descubrían continentes, la ciencia médica evolucionaba alargando y haciendo mejorar las condiciones de la existencia, pero la discriminación de las mujeres se reflejaba en su ausencia de las primeras Declaraciones de Derechos: la americana de Virginia de $1776^{3}$ y la francesa Declaración de Derechos del Hombre y del Ciudadano de 1789. Ambas iniciaban un período histórico. Por primera vez se hablaba de derechos con vocación de universalidad, pero también se mantenía la marginación del 50 \% de la humanidad. Un $50 \%$ necesario para su existencia.

Por ello, escribir sobre la presencia de las mujeres en los parlamentos a lo largo de todos estos años de democracia induce a recordar: la lucha de las mujeres para que sea real y efectivo el derecho reconocido en el artículo 23 de la Constitución de "participar en los asuntos públicos directamente o por medio de representantes libremente elegidos en elecciones periódicas por sufragio universal... y a acceder en condiciones de igualdad a las funciones y cargos públicos con los requisitos que las leyes señalen" (art. $23 \mathrm{CE})$.

A lo largo de la historia la presencia de las mujeres en el espacio público se ha visto mediatizada por diversos factores religiosos, sociales y también coyunturales, siempre arbitrarios que hoy no soportarían un análisis mínimamente lógico. Como diría Galileo e pur si mouve. Esa irracionalidad de la exclusión de las mujeres del "todos" de las primeras Declaraciones de Derechos, fue el detonante que unió las reflexiones habidas por las primeras teóricas de la igualdad, con las demandas reales de mujeres como Olimpe de Gouges o las que protagonizaron el movimiento sufragista.

Y es que nuestro siglo XIX es un ejemplo de la marginación de las mujeres de los derechos de ciudadanía: la Constitución de 1812, como ejemplo próximo, excluía directamente a las mujeres de la nacionalidad: "son españoles todos los hombres libres nacidos y avecindados en los dominios de las Españas, y los hijos de estos", y convivía con la incongruencia de que las mujeres podían reinar pero no tener los derechos de los que eran titulares sus súbditos, o con la de transmitir un derecho que no poseían. Se las equiparaba, al negarles este derecho, a los hombres procesados criminalmente y que estuviesen en prisión, los que hubiesen padecido penas corporales aflictivas o infamatorias y no hubiesen sido rehabilitados, los que estuvieren bajo interdicción ju-

2 El tratamiento de la violencia de género en la prensa en las páginas de sucesos, su ocultación como caídas o golpes fortuitos.

3 Declaraciones supuestamente universales porque el estado de Virginia mantuvo la esclauitud hasta el final de la Guerra de Secesión, y en la Declaración francesa no se incluía el derecho a voto de las mujeres, ni de los varones no propietarios. No obstante, fueron y han sido un precedente en el ámbito de lo simbólico. 
dicial por incapacidad física o con sus bienes intervenidos y los deudores a los caudales públicos como segundos contribuyentes ${ }^{4}$.

El significado que se dio, y aún persiste, a la palabra hombre "no fue el de toda persona sino el de varón, y solo sabiendo esto, es decir que el término españoles no incluye a las españolas, se pueden interpretar con claridad los artículos que se refieren a los derechos de participación política de los españoles” (Astola, 2008: 33-54).

Siguiendo este razonamiento de negación a las mujeres de los derechos de participación política, ya en el siglo XX, volvemos a encontrar razones esporádicas que añadir a la historia del derecho al sufragio femenino como es el reconocimiento del derecho al voto a las mujeres francesas en 1944 y a las italianas en 1946 al finalizar la Segunda Guerra Mundial. ¿Influiría su participación en la guerra? Se habían ganado este derecho (no bastaba la nacionalidad) ${ }^{5}$. Con anterioridad las mujeres británicas mayores de 30 habían conseguido el derecho a votar en el año 1918, aunque tuvieron que esperar a 1928 para que se igualara la edad de las mujeres a la de los hombres para poder votar, es decir, a los 21 años.

En el ámbito internacional, también Naciones Unidas, creada en plena guerra mundial, aprobó en 1948 la Declaración Universal de Derechos Humanos. La Comisión de la Condición Jurídica y Social de la Mujer, presidida por Eleanor Roosvelt, defendió con éxito la necesidad de suprimir las referencias a "los hombres" como sinónimo de la Humanidad y logró incorporar un lenguaje nuevo, más inclusivo en el texto de la Declaración ${ }^{6}$. La guerra también habría logrado atraer la atención sobre la situación de los derechos de la mujer y visibilizar su diferente situación respecto a los hombres como sujetos de derechos.

Puede que por ello, la ONU, entre 1947 y 1962, se centrase en establecer normas y formular convenciones internacionales que cambiaran las leyes discriminatorias y aumentaran la sensibilización mundial hacia las mujeres. En 1953 se aprobó el Convenio sobre los derechos políticos de la mujer, en 1966 el Pacto Internacional sobre los derechos civiles y políticos, y 1975 fue declarado Año Internacional de la Mujer. Luego se sucedieron las Conferencias Mundiales en México (1975), Copenhague (1980), Nairobi (1985) y la que más trascendencia tuvo, la celebrada en Beijing (1995), que aprobó una declaración final de gran impacto que, entre otras cosas, insistía en la necesidad de garantizar un reparto equilibrado de las responsabilidades, de los poderes y de los derechos.

El Derecho Comunitario reconoció el principio de igualdad de trato por razón de sexo en la normativa que emanaba tanto de la Comisión como del Parlamento. Ambas

\footnotetext{
4 Las referencias a las constituciones históricas son de Constituciones y otras leyes y proyectos políticos de España (1969). Editora Nacional. Madrid, 2 vols.

5 Las suizas no lo lograron hasta 1971

6 Seres humanos, art. 1; toda persona, art. 2; todo individuo... Los hombres y las mujeres (matrimonio).
} 
instituciones manifiestan su preocupación por la ausencia o presencia testimonial de las mujeres en los puestos de decisión pidiendo a los partidos políticos "que establezcan sus listas de candidatos según un sistema de cuotas... definido y controlable para que se alcance la igualdad numérica de hombres y mujeres en todos los órganos de representación política" (Resolución del Parlamento Europeo 169 de 1988). El Consejo de Europa abordó la presencia de las mujeres en los espacios de poder en la conferencia sobre El principio democrático de igual representación. Cuarenta años de actividad del Consejo de Europa (1989), donde surgieron dos importantes ideas: el concepto de democracia paritaria y la propuesta de incluir el principio de igualdad entre mujeres y hombres en un protocolo adicional a la Convención Europea de Derechos Humanos?.

\section{LA PARTICIPACIÓN POLÍTICA DE LAS MUJERES: CORTES GENERALES Y PARLAMENTOS AUTONÓMICOS}

El periodo que estamos tratando de nuestra historia como ciudadanas, empieza con la Transición. Las asociaciones de mujeres, poco reconocidas oficialmente hasta bien entrado el siglo XX cuando Naciones Unidas en 1979 adopta la Declaración sobre eliminación de la discriminación contra la mujer, tuvieron una participación muy destacada, que aún continúa en la defensa de los derechos de las mujeres. De forma esquemática se puede definir el movimiento feminista como "las organizaciones de mujeres que allá por los siglos XVIIl y XIX reclamaban los derechos civiles y democráticos, disfrutados solo por los hombres" (Sevilla, 2006: 9). No se entendería el reconocimiento de los derechos de la mitad de la población sin su presencia en el espacio público ${ }^{8}$. Su proyecto era formar parte del cambio. Vinculadas a partidos políticos se enfrentaban a la dificultad que siempre ha existido para las mujeres de lo que más tarde se ha llamado conciliación: de su papel exclusivo en la esfera privada con su deseo de participar como derecho propio en la vida pública?.

El voto siempre es importante, el de las mujeres también: “Todos los partidos políticos desde la derecha a la izquierda son conscientes de que el voto de la mujer va a ser decisivo para llevarlas al Congreso e incluyen por lo tanto en los programas electorales el tema mujer" (Escario et al., 1996: 266). Aunque figurase en la parte final junto a temas considerados de segundo orden, marginales o de reciente incorporación, se

7 A partir de Beijing en el año 2000 Naciones Unidas adoptó la decisión de celebrar evaluaciones quincenales. La última estaba prevista para marzo de 2020, y cayó como tantas otras cosas por la pandemia (COVID-19).

8 Las referencias al movimiento feminista, así como las de la Transición están tomadas del libro Las mujeres parlamentarias en la legislatura constituyente (2006), en el que también se pone de manifiesto que las elegidas tenían su agenda propia que generalmente iba más allá del pensamiento "oficial" de su partido.

9 En esta época de COVID se ha puesto de relieve la importancia y parcialidad de los cuidados como, entre otros, la reciente publicación de V. Camps, Tiempo de cuidados, otra forma de estar en el mundo, Arpa, 2021. 
hicieron algunas propuestas que resultan reveladoras de lo que los partidos políticos pensaban al respecto:

- El PCE se centra en la defensa de los derechos de la familia, el divorcio civil y la igualdad de la mujer. El PSOE reivindica los derechos fundamentales de la mujer. El PSP apuesta por la adopción de las reivindicaciones feministas.

- Los partidos de centro y derecha abogaban por la plena igualdad, pero desde el prisma de la familia. Humanismo cristiano y tradición liberal europea en UCD y concepción cristiana de la familia y sus valores permanentes en AP.

Las formaciones políticas eran conscientes de que las nuevas Cortes tenían que afrontar una serie de reformas legales que necesitaba una sociedad moderna y algunas coincidían con las que pretendían las asociaciones de mujeres. Una revista de la época, Guadiana, entrevistó a diputadas de diferentes partidos para conocer su proyecto sobre la mujer. Soledad Becerril de UCD piensa que:
la situación de la mujer en la sociedad española es compleja y difícil... debemos presionar para que todos nuestros problemas se resuelvan, pero debemos hacerlo junto al hombre... igualdad con el hombre en el acceso al trabajo, evitar leyes paternalistas... respecto al divorcio el Estado debería regular el matrimonio civil para quienes no deseen casarse por la Iglesia.

Lo prioritario para Carlota Bustelo, diputada por el PSOE, era elaborar una Constitución donde estuviesen enmarcados estos problemas:

\footnotetext{
Derecho al divorcio y al aborto, libertades personales, la anticoncepción en el marco de la Seguridad Social, separación Iglesia y Estado, leyes civiles de matrimonio y posibilidad de divorcio, equiparar a la mujer y al hombre en el marco legislativo y laboral, crear una infraestructura suficiente para que la mujer pueda estudiar y trabajar en igualdad de condiciones, creándose guarderías y comedores, etc., en lugares de trabajo y en los barrios.
}

Pilar Bravo del PCE coincidía con Bustelo respecto al divorcio, planificación familiar, despenalización del adulterio y "de todas las leyes que discriminan a la mujer en cualquier materia... hacer partícipe a la mujer en todos los órdenes de la vida y el principio de igualdad, educación sin discriminaciones".

Por último, la diputada por Alianza Popular, María Victoria Fernández-España, vincula la igualdad con el tipo de sociedad en que se vive: "Una sociedad será libre, democrática y justa cuando hombres y mujeres sean iguales ante la ley, cuando se liberen ambos de los residuos de la educación machista que afecta tanto al hombre como a la mujer...", y en este caso, estamos hablando de la participación en uno de los derechos básicos de la ciudadanía (Sevilla, 2006: 39). 
La existencia de un sistema democrático parte de un supuesto previo: el pueblo es el titular de la soberanía (art. 1.2 CE) que se ejerce mediante el sufragio y que implica dos exigencias que el ordenamiento debe garantizar: a) que el sufragio sea universal, igual, libre, directo y secreto, y b) el general y libre acceso del pueblo al sufragio pasivo, ya que en caso contrario los ciudadanos solo elegirían, pero no desempeñarían el poder (Aragón, 2000).

Los resultados electorales de 1977, con relación a la presencia de mujeres en las cámaras, defraudaron a las asociaciones de mujeres que acudieron al Congreso el 13 de julio para expresar su protesta y mostrar su apoyo a las elegidas. Entregaron un manifiesto en el que también expresaban su solidaridad:

Somos conscientes que no está representado (el movimiento feminista) en estas Cortes, que de las 658 mujeres propuestas como candidatas sólo han resultado elegidas 25, por estar las mujeres situadas en los últimos lugares de las listas e ir de relleno, y de ellas, solo tres [se referían a Carlota Bustelo (PSOE), Dolors Calvet (PSUC) y Asunción Cruañes (PSOE)] han demostrado con su trabajo y su lucha su condición de feministas. A estas tres mujeres nos dirigimos porque consideramos que son quienes mejor pueden defender nuestros intereses.

En los debates de esta legislatura constituyente y ordinaria se demuestra la importancia de la participación política de las mujeres para la defensa de sus derechos e intereses que se vinculaba al feminismo como teoría política y movimiento social ${ }^{10}$.

Lucas Verdú (1981-82: 40) al referirse a nuestra Constitución indica que "el constituyente español no se ha percatado de la situación de la condición femenina en nuestra Patria" considerando insuficiente el tratamiento constitucional en cuanto a los derechos de las mujeres que, en su opinión, debería haberse abordado con la

inclusión de una norma en el Capítulo III del Título I que contemplase la específica situación de la condición femenina y serviría para que el legislador, el juez y la

10 Junto a lo que se consiguió hay que subrayar el fracaso que supuso para las mujeres la redacción del artículo 14: incluir la discriminación por razón de sexo como una causa más, "la tercera" cuando es constatable que afecta al 50 \% de la humanidad y que se superpone a las otras causas de discriminación.

Y sigue que los defendieron: La investigación que la vicepresidenta del Gobierno, María Teresa Fernández de la Vega, encargó a la Red Feminista de Derecho Constitucional (2006), reveló la labor de nuestras representantes en una legislatura que fue constituyente y fue ordinaria. Todas compartieron el famoso "plante" al abandonar el Pleno para no votar el artículo que consagraba la preferencia del varón en la sucesión de la Monarquía (DS Congreso de los Diputados 108. Sesión Plenaria 37, 12/7/1978 pp. 4170-4171). Al presentarles nuestro trabajo, me permito una licencia personal, las constituyentes se quedaron asombradas y repetían "no nos dimos cuenta de que habíamos hecho tanto". Para la historia quedan sus intervenciones en los debates constitucionales, la magnífica intervención de Teresa Revilla, diputada en la Comisión Constitucional, cuando se aprobó el artículo 14: “...que las mujeres no vamos a dar las gracias por ello...”. Porque incluir el sexo como una más de las discriminaciones y más en segundo lugar "constituye no solo un error de planteamiento sino una subuersión que explica el impasse en que se encuentra hoy en día la igualdad entre los sexos" (Vogel-Polsky, 1988). 
administración adoptasen las medidas pertinentes en bloque, de una sola vez, orientadas a suprimir los condicionamientos femeninos en los planos jurídico, económico-social y cultural sin que cada mujer tuviese que verse obligada a recurrir, en el caso que particularmente le afecte, ante los Tribunales ex artículo 53.2 , con las incomodidades que todo recurso, por preferente y sumario que sea, comporta y con los gastos que ello supone ${ }^{11}$.

Además de las dos partes imprescindibles de un texto constitucional -declaración de derechos y separación o división de poderes- nuestra Constitución tenía un compromiso insoslayable: la organización territorial del Estado que habría instaurado la Constitución de 1931. El artículo 2 sienta las bases del estado autonómico al reconocer y garantizar el derecho a la autonomía de las nacionalidades y regiones que se fundamenta en "la indisoluble unidad de la nación española".

Publicada la Constitución en el BOE el 29 de diciembre de 1978, ese mismo día se registraron los proyectos de estatutos vasco (1979), el primero en llegar, y catalán (1979), que como Galicia (1981), accedieron a la autonomía mediante la disposición transitoria segunda y el procedimiento del artículo 151.2 CE. Andalucía (1981) eligió la vía del artículo 151 CE. El resto de lo que hoy son comunidades autónomas, una vez aprobados sus Estatutos, celebraron sus primeras elecciones el de 8 de mayo de 1983. Todas las cámaras se constituyeron con una mínima presencia de diputadas, ya que los hombres reflejaban en la práctica un ansia por ocupar cualquier espacio de poder, el político también, que hicieron de la presencia de mujeres algo simbólico como si tuviesen un acuerdo tácito que superaba las diferencias ideológicas ${ }^{12}$.

Por extraño que parezca, en las elecciones de 1979, disminuyó el porcentaje de diputadas en las Cortes Generales, respecto a las elecciones de 1977 (5,71 \%, 1978: 5,43 \% y 1982: 4,86 \%) y las elecciones autonómicas presentaban porcentajes similares: 5 diputadas en la primera legislatura de Les Corts (5,62 \%), 4 en el Parlamento de Euskadi (6,67 \%), en Murcia solo 1 (2,33 \%)... La igualdad proclamada en la Constitución y repetida en los textos estatutarios no aparecía en los órganos que representan a la ciudadanía: las Cortes Generales y las respectivas cámaras autonómicas.

La incongruencia es/era que la participación política de las mujeres, esto es, que las mujeres no fueran insensibles a la política, importaba a los partidos. Al menos en el ámbito del discurso. Éramos el 50 \% de su potencial electorado. Quizá por ello en 1983 se crea el Instituto de la Mujer, presidido por Carlota Bustelo, al que siguen organismos similares en las comunidades autónomas.

11 Vide Sevilla Merino (1997) "La presencia de las mujeres en los Parlamentos: las Corts Valencianes”, en Corts. Anuario de Derecho Parlamentario núm. 4 (extraordinario), Valencia, 369-411. 


\section{MUJERES Y POLIITICA}

Pese a la discriminación que suponía la nimia presencia en el poder, las asociaciones de mujeres seguían defendiendo su derecho a participar, a "la mitad del cielo, la mitad de la tierra y la mitad del poder" (Declaración de Atenas 3/11/1992) ${ }^{13}$. Desde la Academia, las profesoras universitarias integrábamos esa parte en nuestras clases. Investigábamos también en jornadas más reducidas la situación de las mujeres como sujetos de derechos en el Estado, qué significaba el texto constitucional desde nuestra perspectiva... También se crearon institutos o seminarios que agrupaban distintas materias científicas como Emakunde en Euskadi, el Institut Universitari d'Estudis de la Dona en la Universidad de Valencia o el Seminario Universitario sobre los Derechos de las Mujeres en la Universidad de Alicante,...

Obviamente, desde la creación del Instituto de la Mujer se potencian las actividades tendentes a lograr la igualdad de las mujeres. En 1987 la Fundación Pablo Iglesias organiza un curso sobre Mujer y participación política desde una perspectiva sociológica con intervenciones de teóricas del feminismo y mujeres con responsabilidades políticas o interés por la relación entre "política y mujeres". El objetivo era reflexionar desde la teoría e intentar articular estrategias prácticas para aumentar la participación y producir los cambios necesarios para eliminar los factores que causan la discriminación política de las mujeres. El interés de los partidos por las mujeres era como posibles electoras, no como compañeras de escaño. Los partidos eran más proclives a fomentar espacios de mujeres para que se ocuparan de las "cuestiones" de las mujeres que a introducir cambios en sus debates o a incorporar mujeres en las listas ${ }^{14}$.

Para Judith Astelarra (1990: 15) las mujeres participaban activamente en asociaciones y movilizaciones ciudadanas como las del consumo, en asociaciones de los colegios, mucho tiempo llamadas de padres, aunque la mayoría de quienes las formaban fuesen mujeres, asociaciones de barrio o similares que no pueden considerarse de "poder"15. Esto no quiere decir que las mujeres no se interesaran por los temas de la política o por el espacio público, más bien la sobreabundancia de sus ocupaciones en lo privado les impedía de facto la participación. Esa era la realidad del momento. Como dato que con-

13 La reciente publicación de Alicia Miyares (2021) Distopías patriarcales destaca la importancia de esta cumbre europea de "Mujeres en el poder".

14 En el ámbito de la Comunitat Valenciana se creó el Consell de Cultura del que formaban parte 21 miembros. En 1985 Les Corts solo eligieron hombres. En 1993 fui elegida por Les Corts como adjunta al Síndic de Greuges. El Estado y las comunidades autónomas tenían una figura similar. En 1993, solamente tres mujeres formábamos parte de estas instituciones: la Adjunta al Defensor del Pueblo estatal, la adjunta al Ararteko y yo. Es solo un ejemplo entre los muchos que se pueden encontrar.

Es lo que coloquialmente se conocía como la decisión de la cerveza. Cuando se acababa la reunión formal, las militantes se iban a casa, urgidas generalmente por su condición de madres, etc., y los hombres se quedaban tomando una cerveza y ahí es donde surgía quienes podrían ocupar.. lo que fuere.

Una exposición complementaria en la obra ya citada La presencia de las mujeres en los Parlamentos... La introducción complementa los antecedentes de la relación de las mujeres con "lo público". 
trapone su supuesto desinterés por lo público, está la historia, las pinturas (los cuadros de Goya), los relatos escritos que muestran que las mujeres siempre han tomado parte activa en las revoluciones y en las guerras.

Para Bitte Nordstrom (1990: 24) "una diferencia biológica entre hembra/macho, en relación con la reproducción biológica de seres humanos, ha constituido la base para una diferenciación social asimétrica entre varón y mujer con la colaboración y la ayuda instrumental del poder político..." también otros poderes como el económico, el religioso, el filosófico, partidarios de un cierto inmovilismo, han contribuido a ello. Pero, en su opinión, "sin la participación de las mujeres ni se conseguiría un nuevo orden económico, ni un sistema de género/sexo pacífico”. Pero esa realidad no ha sido reconocida ni por la política ni por la economía. En los años 80 un porcentaje alto de mujeres tenían una posición social que dependía del marido, si trabajaban su salario era considerado como un complemento del que se podía prescindir para dedicar su tiempo al cuidado, además de la violencia física también difícil de demostrar ${ }^{16}$.

El planteamiento de Carmen Martínez Ten (1990: 39) era que "las transformaciones ocurridas en los últimos años en ámbitos como la familia, la educación o el trabajo asalariado no se han reflejado en el campo de la política y la presencia creciente de la mujer en la universidad o el mercado de trabajo no ha tenido correspondencia en la esfera del poder político".

La participación de las mujeres en el poder político era necesaria para conseguir un avance en democracia. Para ello había que cambiar las reglas desde dentro, "hace falta, ante todo, que en los órganos de decisión política haya mujeres capaces de recordar sus intereses específicos a expensas de ideologías partidarias o de realismos que solo corresponden a la realidad masculina. Las reglas de juego son malas pero peor es no jugar y dejar que sean otros quienes decidan sobre la vida de las mujeres" (Martínez Ten, 1990: 41). La que luego sería directora del Instituto de la Mujer hablaba de los incipientes cambios en la familia, en la educación, en la incorporación de mujeres al trabajo extradoméstico pese a que la tasa de actividad femenina en España es más baja frente a otros países desarrollados o frente a la tasa de actividad masculina.

Es interesante, para el ámbito de este trabajo, el dato de afiliación de mujeres a partidos políticos en 1984. Solo superaban el $30 \%$ : Alianza Popular $33 \%$, CDS 32 \%, y PCE $30 \%$. Destaca Euskadiko Ezkerra que roza el $40 \%$. En cuanto a las organizaciones sindicales que, en parte, reflejan la incorporación de las mujeres al mercado de trabajo -al menos al trabajo reglado porque el doméstico era más bien oculto-, UGT y CCOO declaran un porcentaje de afiliación próximo al 10 \%. Martínez Ten destacaba que:

16 Aún no se hacía el cálculo de lo que significaba el "no trabajo" de las mujeres en el PIB del Estado como haría la profesora María Ángeles Durán desde su cátedra de Sociología. Defendió la incorporación a la Contabilidad Nacional las horas de trabajo doméstico El ama de casa. Crítica política de la economía doméstica (1978) que tuuo gran impacto internacional. Desde la Primera Conferencia de Naciones Unidas sobre la Mujer en 1975 (México) urgió la incorporación del trabajo no remunerado en la investigación económica. 
...la supremacía masculina entre los cuadros directivos de los partidos políticos se refleja a la hora de elaborar las listas electorales, no solo en cuanto al porcentaje de mujeres sino, lo que es más importante, en lo referente a su orden de inclusión en la lista que -como sabemos- es determinante para la posibilidad de elección... La militancia de mujeres era inferior a la proporción de mujeres socialmente activas, mucho menor en las candidaturas y aún menor en los puestos clave.

Como ejemplo de las estratagemas de los partidos políticos para aparentar la incorporación de mujeres, las listas del PSOE en las elecciones de junio de 1986: presentó 48 mujeres en las listas al Congreso, solo 13 de ellas en la primera mitad de la lista y solo 1 de cabeza de cartel. AP presento 51 mujeres, pero solo 16 en la primera mitad de la lista y 2 como cabeza de candidaturas.

La conclusión no presentaba un panorama muy halagüeño si se añade el dato de que las mujeres que mostraban más interés y posibilidades en la participación política eran las que tenían ya una doble jornada: trabajo asalariado y doméstico que deberían triplicar si entraban en política ${ }^{17}$.

Para Celia Amorós (1990: 107), que también tiene la virtud de la ironía y el humor:

las mujeres nos sentimos poco motivadas para participar en las instituciones de la política. Tampoco las instituciones de la política se prestan al acceso de las mujeres... a partir de ciertos niveles las mallas se estrechan y nosotras no pasamos... el poder crea sus propios espacios. Los sujetos hegemónicos crean sus propias valoraciones sociales, no necesitan reprimir porque solo ellos producen discursos significantes y legítimos, que tienen valor.

Y citando a Marx, añadía que "las ideas de la clase dominante son las dominantes...”.

“Cuando las feministas decimos que 'lo personal es político', prosigue C. Amorós (1990: 111), "queremos decir que el nivel de abstracción en que se ha construido la política es inadecuado, justamente porque ha hecho abstracción de, es decir, ha puesto aparte 'lo personal'...". El feminismo como ética propone a las mujeres hacer política, pero no cabe duda de que se trata de que la hagan para las mujeres... la mera universalización de acceso al poder -que tengan poder más individuos trascendiendo los genéricos- sería en sí mismo un valor ético desde el punto de vista, al menos respetable para todo el feminismo, de una ética ilustrada... La crítica feminista de la política se configura como la propuesta de diferentes agentes e instancias de decisión acerca de lo que hay que incluir y lo que hay que poner aparte, del trasiego entre lo público y lo privado. 
Termina su intervención de una forma curiosa (Amorós, 1990: 115):

Si resulta que por incorporarnos a la política nos sale barba y nos convertimos en San Antón, el mundo no se hundirá porque haya más "sanantones" y nos toque nuestro turno. Si resulta que somos tan diferentes que sale la Purísima Concepción, miel sobre hojuelas y transfiguraremos a San Antón. Pero no parece razonable renunciar a San Antón por si no sale la Purísima...

El primer impulso del feminismo moderno, en el siglo XIX, exponía Marina Subirats, va en el sentido de conseguir el derecho a la individualización para las mujeres, es decir, el derecho a escapar al destino y a la limitación, genéricos, y a vivir vidas personalizadas que puedan desarrollarse en la esfera de lo público. La lucha se plantea en el terreno de la igualdad de derechos, pero detrás de ella hay un gran número de implicaciones; se trata de poder entrar en el mundo de los hombres, de poder actuar como ellos, y por consiguiente, de ser mujer, ser definido por el conjunto de limitaciones genéricas, a ser individuo, a ser persona... El problema no se sitúa globalmente en términos legales, sino de prácticas sociales, la sociedad sigue valorando más a los hombres. Pero los efectos son reales: "todas las esferas que comportan un ejercicio directo del poder muestran fuertes resistencias a la entrada de mujeres... también para los hombres la lucha por el poder entre ellos es exacerbada... solo acceden a renunciar a pequeños espacios si se produce una fuerte presión colectiva de las mujeres"18.

Dolors Renau (1990: 240) planteaba el dilema al que se pueden enfrentar las mujeres cuando participan en primera persona de la política: "Si la 'identidad femenina' es el resultado de nuestra historia, de nuestras virtudes -que las tenemos y muchas, aunque no hayan entrado ni en el mundo oficial ni en la cultura-, ¿cómo hacer para preservarlas y para que se incorporen al Estado sin que perdamos lo que tenemos?".

Carlota Bustelo (1990: 275), directora del Instituto de la Mujer ${ }^{19}$, había sido parlamentaria en la legislatura constituyente, sumaba también esta experiencia:

El feminismo, decía, se puede ejercer desde ámbitos muy distintos y desde posturas muy diferentes, los caminos pueden ser distintos pero todos válidos... sería importante definir los objetivos, los plazos y estrategias para alcanzarlos, ponernos de acuerdo sobre el trabajo ¿tiempo parcial, reducción de jornada, reparto del

18 Subirats reflexionaba sobre lo que influyen las "nociones culturales profundamente ancladas en nuestros prejuicios y que son cotidianamente reforzadas en el entorno, en los medios de comunicación, en la escuela, en la familia" (Subirats, 1990: 117-131). La entrevista de El País (2/5/1999) a las candidatas cabezas de lista es un ejemplo. En las elecciones europeas de 1999, los partidos Popular y Socialista presentaron como cabezas de lista a Loyola de Palacio y a Rosa Díez. El País les hizo una entrevista a ambas que he puesto muchas veces como ejemplo de la imagen de las mujeres en los medios. Las preguntas eran ¿cuál es la última película que le ha conmovido? ¿qué político del partido rival le gusta más? Dé tres razones para ser vegetariana. ¿A quién se amarraría para echar un baile? ¿Se pondría top less en la playa? ¿Qué importancia tiene el sexo en su vida? ¿A quién pide asesoramiento sobre su imagen? Preguntas como con qué político de la oposición bailaría o si se pone top less en la playa... no creo se las hayan hecho nunca a ningún político. 
trabajo? ¿Cómo hacemos para superar la segregación laboral, es decir que no haya trabajos masculinos y femeninos que es uno de los grandes problemas de todas las mujeres del mundo?

Siguiendo el Plan de Acción de las Comunidades Europeas ${ }^{20}$ presentó el plan del Instituto de la Mujer que era, dijo, "el resultado de un Informe sobre la situación social de las mujeres que hemos elaborado en el Instituto con todos los estudios y recogida de datos que hemos hecho durante estos años"21.

Para Bustelo (1990: 279) "son objetivos bastante ambiciosos a pesar de lo cual creo que el movimiento feminista debería ir bastante más allá de lo que yo he asumido, como contenido de las grandes líneas del Plan de Igualdad". Indudablemente el contenido era ambicioso para la época. Tuvieron que pasar muchos años para que se aprobasen las leyes estatal y autonómicas, algunas de ellas se adelantaron a la ley estatal.

\section{EL CAMINO A LA PARIDAD}

Ya hemos visto que la preocupación por la relación de las mujeres con el poder y la del poder con las mujeres era motivo de interés para los actores políticos nacionales, europeos e internacionales. Nadie que pensara que la democracia era la mejor forma de organización política podía sentir indiferencia ante el escaso número de mujeres en las cámaras representativas de los Estados europeos: Francia en 1993 tenía un porcentaje de diputadas del 6,41\%, Austria y Alemania rondaban el 27 \% en 1994, Bélgica en 1995 el 12 \%, Dinamarca en 1994 el 33 \%, Finlandia en 1995 el 33 \%, Grecia en 1996 el 6,33 \%,

20 Desde 1978 la Unión Europea aprueba directivas sobre la igualdad de trato entre mujeres y hombres en seguridad social, acceso a bienes y servicios... Igualmente, el TJUE también ha ido creando jurisprudencia sobre igualdad de retribución, 1976 caso Defrenne, sobre exclusión del régimen de pensiones a tiempo parcial como discriminación indirecta de las mujeres...

21 1. Perfeccionar el desarrollo normativo del principio constitucional de igualdad, y no discriminación por razón de sexo, conseguir una mayor aplicación de la legislación vigente en fauor de las mujeres.

2. Conseguir el acceso a la información de todas las mujeres a mayores niveles de información, formación y cultura y fomentar un reparto más equilibrado de las responsabilidades familiares y domésticas entre hombres y mujeres.

3. El ejercicio libre y responsable de la maternidad-paternidad no solo como derecho individual sino como formación social que debe contar con la suficiente protección social para hacerla compatible con el derecho de las mujeres y varones, al libre desarrollo de la personalidad

4. Una mejor protección de la salud de toda la población femenina y especialmente de los grupos de mujeres expuestos a mayores riesgos.

5. Diversificar más opciones escolares de las jóvenes y ampliar su participación en actividades culturales.

6. Reducir la tasa de desempleo femenino en la segregación laboral por razón de sexo.

7. Mejor y mayor protección social de los colectivos femeninos más marginados y un mayor desarrollo de los servicios sociales en general.

8. Mayor participación de las mujeres en la vida política y especialmente en los niveles de máxima responsabilidad.

9. Iniciar programas de cooperación internacional que tengan como objetivo beneficiar a grupos concretos de mujeres.

10. Mejorar y completar el conocimiento de la situación social de las mujeres españolas y la influencia en ella de las medidas de política social y económica, a través del perfeccionamiento de las estadísticas, realización de encuestas e investigaciones, el análisis de la variable sexo y cualquier estudio que se lleve a cabo y el diseño de los indicadores sociales necesarios. 
Italia en 1996 el 11,11 \%, Portugal en 1995 el 13 \% y Noruega en 1997 el 36,36 \%. España en 1989 tenía el 12,72 \% de diputadas y en 1993 el porcentaje subió al $16 \%{ }^{22}$. Con estos datos la imagen de la mayoría de las cámaras legislativas europeas, también de la totalidad de nuestras cámaras autonómicas, se parecía poco a la fotografía de cualquier calle de nuestras ciudades.

Los partidos políticos, más bien sus ejecutivas o los órganos que detentan el poder son los que deciden el contenido del programa, las estrategias de actuación y quienes confeccionan las listas electorales. A ello se añade que la participación de las mujeres es fundamental para la democracia: "difícilmente pueden los partidos ser cauces de manifestación de la voluntad popular e instrumentos de una participación en la gestión y control del Estado que no se agota en los procesos electorales, si sus estructuras y funcionamiento son autocráticos" (STC 56/1995).

A los partidos, insistimos, les interesan las mujeres como votantes. Sin ninguna originalidad crearon ramas femeninas y trataron de incluir temas que interesasen a las mujeres, pero sin compartir el poder real. Y sobre todo lejos de "uno de los objetivos centrales del feminismo -señalaba Neus Campillo (1997) - es luchar contra la amplia aceptación de los valores masculinos como hegemónicos y sobre todo cambiar la visión de aquello que hacen y representan las mujeres tiene menos valor que lo que hacen y representan los hombres, aunque se trate de la misma cosa". Y eso solo se puede hacer desde el poder.

Coincidimos, en parte, con la opinión de Rodrigues Canotilho (2012: 103-118): "Hay pocas materias en las cuales el Derecho Constitucional de la Unión Europea -tanto de origen legislativo como jurisprudencial- haya tenido una influencia tan positiva en el Derecho Constitucional de la mayoría de los Estados miembros como la igualdad de género ${ }^{23}$. El Derecho europeo es, de hecho, fuente sorprendente de derechos de las mujeres".

La Unión Europea desde el principio manifestó su preocupación por la desigualdad de las mujeres. En el acceso a la representación se aprobó una directiva en 2012 en cuya exposición de motivos se afirmaba que "las mujeres siguen estando insuficientemente representadas, un $24 \%$ en los parlamentos nacionales y el $31 \%$ en las asambleas y parlamentos regionales...”. El Parlamento Europeo desde su constitución en 1979 con un 15,2 \% de parlamentarias ha llegado en la actualidad (2019-2024) al 40,4 \%, España al $47 \%$ (24/17). El resto de los Estados presenta diferentes porcentajes desde Chipre

22 El Partido Socialista en su XXXI Congreso federal incorpora a los estatutos federales la adopción de un sistema de cuotas "de representación de mujeres en un porcentaje no inferior al 25 \% en cada uno de sus ámbitos. La presión de las afiliadas logro que en el XXXIV Congreso "El partido se pronuncia por la democracia paritaria entre hombres y mujeres... ningún sexo tenga menos del 40 \% ni más del $60 \%$ ".

23 Se ha hecho común la expresión "género" al hablar de igualdad de las mujeres. Según la Unión Europea "sexo es que las mujeres dan a luz a sus criaturas, género es que son las que las tienen que cuidar a ellas, a la casa, a los hombres de la casa..." No es compatible tener una ley contra la violencia de género y hablar de la igualdad de género. Por eso las leyes de igualdad se llaman simplemente leyes de igualdad. Aquí respetamos el texto de la autora. 
con 0 mujeres, la paridad a favor de las mujeres en Suecia (11/19), Finlandia (7/6), Dinamarca (6/7), Irlanda (5/6), Países Bajos (13/3), Francia (37/37) y Eslovenia (4/4). Mayoría de hombres en Bulgaria (5/12), Rumanía (7/25), Lituania (3/8), Polonia (18/33), Chipre (0/6), Grecia (5/16), República Checa (7/14)...

Con los datos de mujeres en los espacios de poder era evidente la "débil" voluntad de los partidos políticos para garantizar la presencia de mujeres en las cámaras que representaban a la ciudadanía. Estas reformas fueron consideradas inconstitucionales y rechazadas como tales por los tribunales encargados de velar por la concordancia entre ley y constitución. De nuevo es importante la política de presencia, ¿en cuántos partidos políticos es una mujer quien ostenta el cargo directivo de mayor responsabilidad?

Aunque resultase un procedimiento complejo la situación era tan difícil de resolver que fue necesario reformar las Constituciones para, como es lógico por otra parte, garantizar un derecho. Las reformas fueron: 1994 Alemania, art. 3.1; 1997 Portugal, art. 109; 1999 Francia, arts. 3 y 4; 2002 Bélgica, arts. 10 y 11 bis y 2003 Italia, arts. 3, 49 y $51^{24}$.

España no fue una excepción. El Partido Popular (PP) se oponía a cualquier reforma de la ley electoral que pretendiese "condicionar" la libertad de los partidos políticos. A medida que los partidos se autovinculaban por resoluciones internas a la presencia de mujeres, aumentaba su porcentaje en las listas, siempre considerablemente inferior a la de los hombres. Así en la IV legislatura el GP Popular había pasado de un porcentaje de 7,14 \% de diputadas en la legislatura anterior al 17,38 \%. Y el GP Socialista de 7,07 $\%$ en la III legislatura al $17,16 \%$ en la IV. Un aumento considerable se produce en la VIl legislatura: el GP Popular el 25,14 \% y el GP Socialista el 36,80 \%. Pero el PP no era partidario de que "constriñeran su libertad en la composición de listas". De hecho, y para demostrarlo, fueron los primeros en proponer mujeres para ocupar la presidencia del Congreso y del Senado y también, más adelante, la presidencia de las Comunidades Autónomas ${ }^{25}$.

24 Reformas de las Constituciones:

- Constitución alemana 1994. Art. 3.2: el hombre y la mujer gozan de los mismos derechos...;

- Constitución portuguesa 1997. Art. 109: La participación directa y activa de hombres y mujeres en la vida política de un país es condición e instrumento fundamental de consolidación del sistema democrático;

- Constitución francesa 1999. Art. 3: Son electores... todos los nacionales franceses mayores de edad de ambos sexos... La ley fauorecerá la igualdad entre mujeres y hombres para acceder a los mandatos electorales y cargos electivos";

- Constitución belga 2002. Art. 10: se garantiza la igualdad de mujeres y hombres;

- Constitución italiana 2003. Art. 51: Todos los ciudadanos de uno y otro sexo podrán desempeñar cargos públicos y puestos electiuos en condiciones de igualdad... A tal fin la República promueve con acciones positivas la igualdad de oportunidades entre mujeres y hombres".

En todas ellas aparece el término mujer para referirse a los derechos de ciudadanía. Para adquirirlos es necesario ser nombradas como sujetos con cuerpo, es decir, en femenino... La posesión del propio cuerpo a través de la existencia del lenguaje como ser femenino tiene un efecto inmediato: revela el sujeto político lingüístico y sujetos con cuerpo, es decir, en femenino (Bengoechea, 2005: 37-44). 


\section{CONGRESO DE LOS DIPUTADOS}

Tabla 1. III legislatura (1986-1989)

\begin{tabular}{|l|c|c|c|c|c|}
\cline { 3 - 7 } \multicolumn{2}{c}{} & \multicolumn{2}{c|}{ Hombres } & \multicolumn{2}{c|}{ Mujeres } \\
\hline GP Socialista & 184 & 171 & $92,93 \%$ & 13 & $7,07 \%$ \\
\hline GP Coalición Popular & $\mathbf{8 4}$ & 78 & $92,86 \%$ & 6 & $7,14 \%$ \\
\hline GP CDS & 19 & 19 & $100 \%$ & 0 & $0,00 \%$ \\
\hline GP Minoría Catalana (CiU) & $\mathbf{1 8}$ & 17 & $94,44 \%$ & 1 & $6,56 \%$ \\
\hline GP Vasco (PNV) & 6 & 6 & $100 \%$ & 0 & $0,00 \%$ \\
\hline GP Mixto & $\mathbf{3 4}$ & 32 & $94,12 \%$ & 2 & $5,88 \%$ \\
\hline
\end{tabular}

Tabla 2. IV legislatura (1989-1993)

\begin{tabular}{|l|c|c|c|c|c|}
\cline { 3 - 7 } \multicolumn{2}{c}{} & \multicolumn{2}{c|}{ Hombres } & \multicolumn{2}{c|}{ Mujeres } \\
\hline GP Socialista & 175 & 145 & $82,86 \%$ & 30 & $17,16 \%$ \\
\hline GP Popular & 106 & 95 & $89,62 \%$ & 11 & $17,38 \%$ \\
\hline GP Catalán (CiU) & 18 & 17 & $94,44 \%$ & 1 & $5,56 \%$ \\
\hline GP Federal Izquierda Unida-IC & 18 & 16 & $88,89 \%$ & 2 & $11,11 \%$ \\
\hline GP CDS & 14 & 14 & $100 \%$ & 0 & $0,00 \%$ \\
\hline GP Vasco (EAJ-PNV) & $\mathbf{5}$ & 5 & $100 \%$ & 0 & $0,00 \%$ \\
\hline GP Mixto & 10 & 10 & $100 \%$ & 0 & $0,00 \%$ \\
\hline & 346 & 302 & $87,28 \%$ & 44 & $12,72 \%$ \\
\hline
\end{tabular}

Tabla 3. VII legislatura (2000-2004)

\begin{tabular}{|l|c|c|c|c|c|}
\cline { 3 - 6 } \multicolumn{2}{c}{} & \multicolumn{2}{c|}{ Hombres } & \multicolumn{2}{c|}{ Mujeres } \\
\hline GP Popular & 183 & 137 & $74,86 \%$ & 46 & $25,14 \%$ \\
\hline GP Socialista & 125 & 79 & $63,20 \%$ & 46 & $36,80 \%$ \\
\hline GP Catalán (CiU) & 15 & 13 & $86,67 \%$ & 2 & $13,33 \%$ \\
\hline GP Federal Izquierda Unida & $\mathbf{8}$ & 6 & $75,00 \%$ & 2 & $25,00 \%$ \\
\hline GP Vasco (EAJ-PNV) & 7 & 6 & $85,71 \%$ & 1 & $14,29 \%$ \\
\hline GP Coalición Canaria & 4 & 3 & $75,00 \%$ & 1 & $25,00 \%$ \\
\hline GP Mixto & $\mathbf{8}$ & 7 & $87,50 \%$ & 1 & $12,50 \%$ \\
\hline
\end{tabular}

Fuente: Tablas de elaboración propia. 
A la doctrina tampoco le era ajeno este debate, así se expresa el profesor Juan Cano (1999: 187): “...si bien la participación no es uno de los valores superiores del ordenamiento jurídico configurado como tal en la Constitución, sí que encomienda a los poderes públicos facilitar la participación de todos los ciudadanos en la vida política, como expresión de la sociedad democrática avanzada que se propugna en su Preámbulo". A ello se puede añadir que el Tribunal Constitucional había expresado reiteradamente que el art. 23 no consagra un derecho a ocupar cargos y funciones públicas sino simplemente la prohibición de que el legislador pueda regular el acceso a tales cargos y funciones en términos discriminatorios.

Nada más justificado que regular el acceso de las mujeres "...en igualdad de condiciones a las funciones y cargos públicos con los requisitos que señalen las leyes”, como dice el art. $23 \mathrm{CE}$. Los datos de participación en ese momento, incluso también ahora en algunos casos, muestran la desigual condición en que se encuentran las mujeres en nuestra sociedad como ha reconocido el propio TC en numerosas sentencias ex art. 9.2 CE. Como dice Balaguer "las condiciones de igualdad del art. 23 $\mathrm{CE}$ se interpretan por la jurisprudencia constitucional como una referencia al propio art. $14 \mathrm{CE}$ por lo que no debería estar vedado a medidas de discriminación positiva favorecedoras de la igualdad material" (Balaguer, 2000: 14). Coincidimos en el razonamiento, pero pensamos que no deben ser medidas de discriminación positiva, sino que de lo que se trata es de activar el derecho de las mujeres a la participación política.

Los problemas que sobre derecho electoral se planteaban ante el TC y por la doctrina giraban por ejemplo en torno a "la condición política de extremeños" (STC 60/1987), casos de barreras electorales en aras a impedir la excesiva fragmentación de la Cámara (STC 193/1989) o dar estabilidad al sistema, pero también se desliza que la barrera electoral no es la única fórmula constitucionalmente legítima... En definitiva, el TC abunda en la idea de considerar el derecho a la participación política como un derecho que admite desarrollo legislativo.

Tomando en consideración la jurisprudencia del TC, en noviembre de 2001, el GP Socialista presenta una proposición de ley de reforma de la Ley Orgánica de Régimen Electoral General (LOREG) para modificar el art. 44, que regula la presentación y proclamación de candidatos, y añadir un apartado 4 para que las candidaturas fueran elaboradas teniendo en cuenta el equilibrio entre mujeres y hombres de tal forma que ningún sexo tuviera más del $60 \%$ ni menos del $40 \%$ del total de personas candidatas. Esta proporción es lo que se conoce como criterio básico de la democracia paritaria. La diputada socialista Micaela Navarro advertía que "era una cuantificación numérica de la presencia de ambos sexos a partir de la cual creemos que la sociedad y los partidos políticos se irán acostumbrando a incorporar mujeres y hombres a partes iguales" (DSCD n ${ }^{\circ} 243$, p. 12438 ). Y como ya se había vivido la experiencia de propuestas con porcentajes de mujeres que acababan ubicadas en puestos de riesgo, también se aña- 
de que la proporción se mantenga en el conjunto de la lista y en cada tramo de cinco personas.

También se contemplaba la posibilidad de que en municipios de menor población, inferior a 2000 habitantes, o en circunscripciones a las que por ley correspondiera un número de representantes inferior a 5 , la proporción entre hombres y mujeres sería la más próxima al $50 \%$.

El Grupo Federal de Izquierda Unida presentó una proposición de ley que planteaba la adición de un nuevo punto, el 10, en el art. 46 de la LOREG para que en las candidaturas no existiera una diferencia entre mujeres y hombres superior a uno.

También Iniciativa per Catalunya, desde el GP Mixto, presentó otra proposición de ley que incluía candidaturas con alternancia de mujeres y hombres en las que la proporción no fuera ni más del $70 \%$ ni menos del $30 \%$ de cada sexo, para las elecciones municipales en municipios de 2000 a 10000 habitantes; y la aplicación gradual de esta reforma para que no se tuviera en cuenta en las convocatorias de 2003 y 2004.

Todas las iniciativas fueron rechazadas, pero sirvieron para que los partidos parlamentarios fijasen posiciones en las Cámaras ${ }^{26}$.

\section{PROPUESTAS DE LAS COMUNIDADES AUTÓNOMAS}

Las comunidades autónomas (CCAA en adelante) llevaban su propio ritmo y las cámaras legislativas, en ocasiones, con diferentes mayorías que las que presentaban las Cortes Generales. Casi todas ellas habían aprobado su ley de igualdad entre los años 2002 y 2007 y leyes electorales para las convocatorias autonómicas. Ante la no admisión a trámite de las propuestas de reforma de la LOREG en las Cortes Generales, algunas CCAA iniciaron el camino para dar rango legal y, por lo tanto, garantizar el equilibrio en la representación de hombres y mujeres: "la necesidad de legislar sobre la paridad se ha debido a múltiples factores entre los que se encuentra el comportamiento histórico de los partidos políticos y sus tímidas respuestas internas a la petición feminista de que las mujeres debían estar presentes en los órganos donde se toman decisiones que afectan a toda la ciudadanía" (Campos, 2018: 16).

Las fórmulas propuestas eran alternancia de hombres y mujeres en las listas (Islas Baleares y Castilla la Mancha), lo que se conoce como lista cremallera, o estableciendo porcentajes por tramos como hemos visto proponía el GP Socialista en el Congreso -equilibrio para que ningún sexo tuviese más del $60 \%$ ni menos del $40 \%$ en el conjunto de la lista y en cada tramo de 5 personas-. Y la que propuso la Ley $4 / 2005$, del País 
Vasco, para la igualdad de mujeres y hombres, que en su disposición final añade un párrafo 4 al art. 50 de la Ley 5/1990, de elecciones al Parlamento Vasco:
4. Las candidaturas que presenten los partidos, federaciones, coaliciones o agrupaciones de electores estarán integradas por al menos un $50 \%$ de mujeres. Se mantendrá esa proporción en el conjunto de la lista de candidatos y candidatas y en cada tramo de seis nombres. Las juntas electorales del territorio histórico competentes solo admitirán aquellas candidaturas que cumplan lo señalado en este artículo tanto para las personas candidatas como suplentes.

Llama la atención que solo se refiere a un mínimo de mujeres por lo que su número puede sobrepasarse ${ }^{27}$. De esta forma se abría la puerta a partidos formado solo por mujeres ${ }^{28}$.

Como era previsible, dado el rechazo de las iniciativas presentadas en el Congreso, las leyes aprobadas por las CCAA fueron recurridas por el Gobierno, lo que implica la suspensión de estas. La argumentación del Abogado del Estado se basa en:

$\left.1^{\circ}\right)$ la violación del art. 149.1 CE, competencia en el acceso a los cargos públicos considerando que solo a las Cortes Generales compete, en su caso, la obligatoria distribución igual de las candidaturas en cualesquiera elecciones;

$2^{\circ}$ ) la violación de la reserva de ley orgánica, el recurso considera en base a pronunciamientos del TC (SSTC 38 /1983 y 72/1984)) que "el contenido de la LOREG traspasa el desarrollo del art. $23 \mathrm{CE}$ para abarcar lo que es primario y nuclear en el régimen electoral general"... abarca toda la normativa electoral tanto del Estado como de las "entidades territoriales en que se organiza a tenor del art. $137 \mathrm{CE}$... por lo que un extremo tan importante para el régimen electoral general como es la paridad ha de estimarse incluido en el régimen electoral general reservado a la ley orgánica";

$\left.3^{\circ}\right)$ la violación de los artículos 14 y $23.2 \mathrm{CE}$, quiebra la igualdad jurídica de los elegibles $^{29}$ en nombre de la promoción de la mujer, identificando a la mujer con otras categorías sociales: discapacitado, anciano, marginado... peligrando la afirmación "la Cámara representa al pueblo español";

$\left.4^{\circ}\right)$ que atenta a la libertad de asociación violando el artículo 6 en relación con el 22.1 CE.

27 Democracia paritaria en Euskadi 2001-2016. La participación política de mujeres y hombres en los procesos electorales de la Comunidad Autónoma del País Vasco, (2017) Seruicio Central de Publicaciones del Gobierno Vasco, Vitoria-Gasteiz.

28 Andalucía aprobó en 2003 en la Ley de Medidas Fiscales y Administrativas la paridad en la composición (ni menos de 40 ni más de 60 de cada sexo) de los órganos consultivos y de asesoramiento de la Administración de la Junta de Andalucía. Pero no se logró la modificación de la ley electoral. Aragón y Comunitat Valenciana también hicieron intentos fallidos para aprobar la paridad en las listas. 
El informe del Consejo Consultivo de Castilla-La Mancha afirma la competencia de la comunidad autónoma para regular el sistema electoral propio recogido por el EACM (arts. 10.2 y $311.1^{\mathrm{a}}$ ) y también por la propia LOREG (art. 46.3) que no considera legislación básica los requisitos de las candidaturas (Molina, 2005: 77-100):

\begin{abstract}
La modificación de la Ley Electoral pretende asegurar la composición paritaria de las candidaturas para las elecciones a las CCLM lo que supone establecer una única regla legal que da idéntico trato a todos los ciudadanos de Castilla-La Mancha sea cual sea su sexo... y tiene la virtualidad de operar como una norma de "acción positiva", precisamente porque la regla preexistente, que igualmente otorga el mismo trato legal no ha remediado el resultado peyorativo (la infrarrepresentación de las mujeres...).
\end{abstract}

La normativa electoral de Euskadi que regulaba la igualdad en la representación de las mujeres también fue recurrida por 62 diputados y diputadas del PP, pero al no resolver el recurso hasta 2009 esta norma reguló las elecciones del Parlamento Vasco de 2005 "siendo la única vez que se aplicó con su máxima ratio de aplicación a favor de la igualdad de las mujeres” (Campos, 2010, 2014 y 2018) ${ }^{30}$.

\section{LEY ORGÁNICA 3/2007, DE 22 DE MARZO, PARA LA IGUALDAD EFECTIVA DE MUJERES Y HOMBRES (LOI)}

La solución al deficitario estado de la aplicación de los derechos constitucionales y legales a las mujeres, esto es, la no consideración de las mujeres como sujetos de Derecho, está en el origen de la LOI. La VIIl legislatura de las Cortes Generales (20042008) provoca un cambio en la correlación de fuerzas, además de un aumento de parlamentarias. Si en la VIl legislatura el porcentaje total de mujeres era del 28,29 \% (99 diputadas de 350 escaños), en el GP Socialista el 36,80\% de diputadas (46 de 125) y en el GP Popular 25,14 \% (46 de 183), en cambio en la VIIl legislatura el PSOE obtiene 164 escaños, 76 de los cuales son parlamentarias (46,34 \%); el GP Popular tiene 148 escaños, 42 corresponden a mujeres ( $28,38 \%)$; y en Izquierda Unida, con muy poca representación, 5 escaños, 3 diputados y 2 diputadas ( $40 \%$ ).

La aplicación de las leyes electorales de las CCAA se había suspendido por la presentación de los recursos de inconstitucionalidad. Se inicia la nueva legislatura que tendría que retomar las proposiciones de ley (ahora serían proyectos) presentadas por el GP Socialista que incorporaban porcentajes de mujeres. En lugar de la reforma de la ley electoral lo que se presentó por el Gobierno para su tramitación fue una ley de 
igualdad que, en realidad, suponía una relectura de la Constitución para que las mujeres empezaran a ser sujetos de derechos (Esquembre, 2018: 91-117):

\begin{abstract}
La LOI al desarrollar la igualdad real y efectiva aplicada a las mujeres no tiene más remedio que visualizarlas como sujetos jurídicos, supliendo las deficiencias de la Constitución de 1978, en la que el sujeto constitucional responde a un modelo de persona que solo coincide con los varones. La LOI va a tener que desarrollar algunos aspectos que son más propios de la Constitución, como la definición de sujeto jurídico-político, para que la misma pueda desplegar sus efectos con mayor eficacia. Y es que para que las mujeres se conviertan en sujeto político antes tienen que ser reconocidas como sujeto jurídico ${ }^{31}$.
\end{abstract}

Como diría Rubio Llorente (1993: 17) "la igualdad en la que la justicia consiste condiciona, en efecto, en primer lugar, la forma de constituir la ciudad, de distribuir el poder". La reforma de la ley electoral que contiene la LOI apunta a esta frase definiendo la igualdad como una forma de justicia que interviene en la constitución de un Estado y en la forma de distribuir el poder. Es el fin último de la LOI no solo por la reforma de la ley electoral sino por todos los artículos que se refieren a la distribución del poder (arts.16, 37, 38, 52-54 y 75).

A estas premisas responde la disposición adicional primera cuando define el principio de paridad o composición equilibrada como expresión de calidad democrática. Como se dice en el Preámbulo: "Se asumen así los recientes textos internacionales en la materia y se avanza en el camino de garantizar una presencia equilibrada de mujeres y hombres en el ámbito de la representación política, con el objetivo fundamental de mejorar la calidad de esa representación y con ella de nuestra propia democracia”. El último fundamento de esta ley, sin desestimar todos los preceptos de la LOI que completan el texto constitucional para la mitad de la ciudadanía, es la disposición adicional segunda. De ahí su carácter de orgánica y también la proliferación de los recursos que pretendieron derogarla. Su contenido motivó el voto en contra de la LOI y la consiguiente interposición del recurso de inconstitucionalidad por el Partido Popular en el que utilizaron argumentos similares a los empleados en los recursos contra las leyes autonómicas:

$\left.1^{\circ}\right)$ la unidad de la soberanía y representación del Estado: que se atribuye a la Nación con carácter único y excluyente y a partir del constitucionalismo democrático al pueblo.

31 Si precondicionamos la igualdad estableciendo unos requisitos determinados, como sería el reconocimiento de dos sujetos constitucionales, tendríamos que retrotraernos a un estado previo a la definición constitucional de igualdad en Pérez Royo (1999), Actas del coloquio "La ley electoral española y democracia paritaria", Fundación Alternativas, Madrid. 
Esta afirmación no impide que se reconozca y garantice el derecho a la autonomía de las nacionalidades y regiones (art. $2 \mathrm{CE}$ ), y que el Estado se organice en provincias, municipios y CCAA (Biglino, 2000: 409-430) 32 .

$\left.2^{\circ}\right)$ La vulneración de la igualdad de toda la ciudadanía al incluir un porcentaje de mujeres, al incluir el sexo como requisito de elegibilidad, lo que quiebra la igualdad jurídica de los elegibles ya que el legislador debe ser neutral respecto al sexo no pudiendo establecer diferencias en la categoría de ciudadano ex arts.14, 23.2 y $68.5 \mathrm{CE}$, por lo que procedería reformar la Constitución. No se podría utilizar el mandato promocional de la igualdad.

El TC ha despejado en diferentes sentencias los reparos jurídicos del recurso. Por todas la Sentencia 222/1992 “...Las diferencias normativas habrán de mostrar un fin discernible y legítimo, articularse en términos no inconsistentes con tal finalidad y deberán, por último, no incurrir en desproporciones manifiestas a la hora de atribuir funciones".

Además, parte de la doctrina ${ }^{33}$ considera que el TC ha hecho una interpretación sistemática de las disposiciones en materia de igualdad (arts. 1.1, 14 y 9.2):

a) sobre la posibilidad de que, en aras de la igualdad, se limite el derecho a la igualdad de trato, es decir, se introduzcan medidas de discriminación positiva $y$

b) tampoco la rigurosa igualdad de trato sea constitucionalmente exigible cuando están en juego derechos fundamentales, como en este caso el de participación.

Al aplicar una diferencia normativa hemos de tener en cuenta su relación con la dignidad de la persona para determinar si la diferencia es o no discriminatoria en cuanto que el resultado afecte peyorativamente a las personas implicadas. El TC justifica, como medidas encaminadas a conseguir la igualdad real, las acciones positivas que el legislador pueda establecer. En su jurisprudencia la referencia al sexo en el artículo 14 supone la decisión constitucional de acabar con la histórica situación de inferioridad atribuida a la mujer.

$\left.3^{\circ}\right)$ El derecho a la libertad de los partidos políticos para confeccionar las listas electorales unido al derecho a ser candidato ${ }^{34}$. Nadie ha puesto en duda el de-

\footnotetext{
32 "Cualquier fórmula que garantice la presencia equilibrada supone la quiebra del principio de que el cuerpo electoral es nacional, aunque el sistema imponga la división en municipios y provincias. El cuerpo electoral no se divide por razón de sexos, no se impone a las personas votar solo a los candidatos de su mismo sexo y quienes resulten elegidas representan a la ciudadanía en su conjunto". Y añado: todos los Diputados representan unas ideas, pero lo que legislan afecta a toda la ciudadanía.

33 Freixes, Biglino, Balaguer, López Guerra, Martínez Sospedra.

34 N. Campillo reflexiona acerca del diferente juicio que merece la misma cuestión según el sexo del sujeto, "mientras el reparto de cuotas se hizo por familias ideológicas nadie planteó problemas de legitimidad... cuando se convierte en una medida contra el sexismo de los partidos políticos es cuestionada como una medida contra los valores de igualdad, libertad y fraternidad..." (Campillo, 1997).
} 
recho de los partidos políticos a regular internamente sistemas de cuota para cualquier elección interna o configuración de listas, pero la cuestión cambia si se regula por ley. Rey Martínez (1999) considera que esta medida podría lesionar la libertad de los partidos políticos para presentar candidatos que libremente seleccionen y afectar a las libertades de asociación, ideología y ejercicio de su actividad. Es cierto que la imposición de incluir mujeres en las listas limita la libertad de los partidos políticos, pero también lo es que los partidos no tienen una libertad absoluta ya que la LOREG impone también otras condiciones, como contrapone Ruiz Miguel (1999: 44-51).

Toda la actividad de los partidos políticos está reglada sin que por ello se considere son limitativas de su libertad, las expuestas son una pequeña muestra. Ante la proximidad de las elecciones autonómicas y locales la Junta Electoral Central aprobó una instrucción en la que se salía al paso de las dudas sobre su aplicación en cuanto a la composición de las listas, se afirmaba su contenido en relación con las CCAA, se impone que se incluya el don o doña precediendo al nombre para evitar dudas sobre el sexo de las personas incluidas en las listas y que las elecciones a las juntas generales de los territorios históricos vascos se regirán por su propia normativa. Tampoco se aplicará en las comunidades autónomas cuya ley electoral sea más favorable a la presencia de mujeres.

Estando de acuerdo en la relevancia de las argumentaciones jurídicas que defienden la constitucionalidad de la reforma de la LOREG proveniente de la ley orgánica de igualdad, sí me gustaría añadir que no coincido con la expresión y por lo tanto calificación de medidas de discriminación positiva que ha utilizado parte de la doctrina y el propio TC al referirse al contenido de este precepto ni tampoco con la denominación de cuotas para referirse al ejercicio por parte de las mujeres del derecho constitucional del art. 23 CE.

La cuestión fundamental para entender el debate es si estamos hablando de cuotas o de regular el legítimo derecho de las mujeres como ciudadanas a la representación. Si, como se ha comprobado, las mujeres no consiguen participar en los órganos a los que se accede con la simple condición de ser ciudadana siendo la mitad del cuerpo electoral y cumpliendo con los requisitos que marcan las leyes, no podemos achacarlo a la casualidad sino a la existencia de una voluntad no expresada pero compartida de marginación, que también podemos calificar de "ambición de poder" apoyada en la tradición. Y se trata de un derecho porque hablar de una cuota cuando estamos hablando del 50 \% de la población de un Estado no es serio. Por eso estamos de acuerdo con los primeros análisis del profesor Rey Martínez en los que definía las cuotas como medidas paternalistas que pretenden "tomar en consideración explícita, como criterio de diferenciación jurídica de trato el sexo” (Rey Martínez, 1999: 56). 


\section{CONCLUSIÓN}

A lo largo de estas páginas he tratado de narrar el cambio que han experimentado los parlamentos en cuanto a la integración de las mujeres. Ha sido necesario su reconocimiento por ley. Por una parte, es lo pertinente: la ley es la que reconoce y garantiza los derechos. Pero en este caso han sido necesarias normas expresas que hablen de mujeres y hombres porque los actores políticos "no entendían" que una representación de la nación no podía parecerse tan poco a cualquier calle de cualquier ciudad. Pero el rostro del poder sigue siendo masculino: jefaturas de Estado, presidencias de CCAA, rectorados de las universidades, partidos políticos, cúspide empresarial y sindicatos... ${ }^{35}$.

En este tiempo de pandemia se ha comparado cómo la gestionaban los países al frente de los cuales estaba una mujer con opiniones favorables sobre la actuación en esta crisis: "Según la presidenta de la Asamblea General de Naciones Unidas la participación de las mujeres en la política promueve la estabilidad económica y contribuye a fortalecer las instituciones" (Naciones Unidas, 2019) ${ }^{36}$. A su vez, manifiesta que "también está demostrado que una mayor representación de mujeres en los parlamentos asegura el avance en las reformas de leyes discriminatorias y un aumento en la inversión en áreas claves como salud, educación y protección social”. Siendo ciertas estas apreciaciones y las que podríamos añadir sobre la influencia que su presencia en los espacios de poder produce, no pienso sea esta la justificación para defender su acceso a las cámaras. Estamos hablando de un derecho de ciudadanía del que los hombres eran titulares solo por su pertenencia al sexo masculino, no por pasar un examen sobre sus aptitudes y actitudes. La igualdad exige que las mujeres accedan de la misma manera, aunque fuesen ciertas estas afirmaciones en las que el factor clave son los programas electorales y la ideología de los partidos ${ }^{37}$.

Como decía una querida compañera: se trata de compartir la vida y, por tanto, de compartir el poder político... Hay que acabar con el canon masculino y la consiguiente consideración de lo femenino como una "desviación" relativamente tolerada mientras se mantenga dentro de unos límites "específicos" que no ponen en cuestión dicho canon (Martínez Sampere, 2000) ${ }^{38}$.

\footnotetext{
35 ¿No es hora de que deje de ser noticia? En las últimas elecciones de Madrid tres candidatas han encabezado candidaturas...

36 ONU: Mujeres en el poder, un evento para reflexionar. (14 de marzo de 2019). AmecoPress [Web]. Recuperado de https://amecopress.net/ONUMujeres-en-el-poder-un-evento-para-reflexionar

37 Hay también sobrados ejemplos en la historia de gobiernos dirigidos por mujeres en los que este análisis no sería aplicable.

38 En igualdad las conquistas pueden no ser definitivas. Un ejemplo de ello: Penélope tejía durante el día y destejía por la noche un manto para que la dejaran tranquila hasta que volviera Ulises. En este caso, basta la falta de acuerdo entre los grupos para que en sus propuestas aparezca la preferencia de un "diputado" para ocupar un puesto singular.
} 


\section{BIBLIOGRAFÍA}

Amorós, C. (1990). Mujer y participación política. En M. Judith Astelarra (Comp.). Participación política de las mujeres (pp. 107-115). Madrid: Siglo XXI de España - Centro de Investigaciones Sociológicas.

Aragón Reyes. M. (2000). Democracia y representación. Dimensiones subjetiva y objetiva del derecho al sufragio. Corts. Anuario de Derecho Parlamentario, 9, 37-60. Recuperado de

https://www.cortsualencianes.es/sites/default/ files/media/file_author/37.pdf

Astelarra, J. (1990). Las mujeres y la política. En M. Judith Astelarra (Comp.). Participación política de las mujeres (pp. 7-22). Madrid: Siglo XXI de España - Centro de Investigaciones Sociológicas.

Astola Madariaga, J. (2008). El género en el lenguaje jurídico: utilización formal y material. Feminismo/s (Ejemplar dedicado a: Mujeres en Democracia: Perspectivas jurídico-políticas de la Igualdad), 12, 33-54.

https://doi.org/10.14198/fem.2008.12.02

Balaguer Callejón, M. L. (2000). Posibilidad constitucional de una ley de igualdad electoral. Actas del coloquio Fundación Alternativas.

Bengoechea Bartolomé, M. (2005). Necesidad de poseer un cuerpo y nombre para acceder plenamente a la ciudadanía. En T. Freixes Sanjuán y J. Sevilla Merino (Coords.). Género, Constitución y Estatutos de Autonomía (pp. 37-44). Madrid: Instituto Nacional de Administración Pública (INAP).

Biglino Campos, P. (2000). Las mujeres en los partidos políticos: representación, igualdad y cuotas internas. En Mujer y Constitución en España (pp. 409-430). Madrid: Centro de Estudios Políticos y Constitucionales.

Bustelo García del Real, C. (1990). Estrategias futuras en la intervención de la administración. En M. Judith Astelarra (Comp.). Participación política de las mujeres (pp. 275-280). Madrid: Siglo XXI de España - Centro de Investigaciones Sociológicas.

Campillo Iborra, N. (1997). El feminisme com a crítica. Valencia: Tandem Edicions, S.L.

Campos Rubio, A. (2010). La igualdad de mujeres y hombres: 30 años de Parlamento Vasco: la Ley 2/2005, de 18 de febrero, para la igualdad de mujeres y hombres. Corts. Anuario de Derecho Parlamentario, 23, 19-45. Recuperado de https: dialnet.unirioja.es/descarga/articulo/3409456.pdf

Campos Rubio, A. (2014). Participación y representación política de las mujeres: el MF y el 100\% de la representación. Revista Vasca de Administración Pública (RVAP), 99-100, 745-764. https://doi org/10.47623/ivap-ruap.99.100.2014.031

Campos Rubio, A. (2018). Democracia paritaria en Euskadi 2001-2016. La participación sociopolítica de mujeres y hombres en los procesos electorales de la comunidad autónoma del País Vasco. VitoriaGasteiz: Servicio Central de Publicaciones del Gobierno Vasco.

Camps, V. (2021). Tiempo de cuidados, otra forma de estar en el mundo. Barcelona: Arpa Editores.

Cano, J. et. al. (1999). Derecho Constitucional. Tomo II, $1^{\underline{a}}$ ed. Madrid: Tecnos.

Constituciones y otras leyes y proyectos políticos de España (1969). Madrid: Editora Nacional. 2 vols.

Escario, P., Alberdi, I. y Lopez-Accotto, A. I. (1996). Lo personal es político: el movimiento feminista en la transición. Madrid: Instituto de la Mujer.

Esquembre Valdés, M. (2018). El reconocimiento de las mujeres como sujetos jurídico-políticos en la Ley de lgualdad. En A. Ventura Franch y S. García Campa (Dirs.). El derecho a la igualdad efectiva de mujeres y hombres. Una evaluación del primer 
decenio de la Ley Orgánica 3/2007 (pp. 91-117). Pamplona: Aranzadi.

García Ninet, J. I. (Dir.) (2007). Comentarios a la Ley de lgualdad. Madrid: CISS.

Lucas Verdú, P. (1981-82). El valor constitucional de la igualdad y la condición femenina. Revista de Política Comparada, 7, 27-49.

Martínez Sampere, E. (2000). La legitimidad de la democracia paritaria. Revista de Estudios Políticos, 107, 133-14.

Martinez Ten, C. (1990). La participación política de la mujer en España. En M. Judith Astelarra (Comp.). Participación política de las mujeres (pp. 39-65). Madrid: Siglo XXI de España - Centro de Investigaciones Sociológicas.

Miyares Fernández, A. (2021). Distopías patriarcales: análisis feministas del "generismo queer". Madrid: Cátedra.

Molina Camacho, J. (2005). La paridad electoral en las Cortes de Castilla-La Mancha: crónica parlamentaria y constitucionalidad de la norma. Corts. Anuario de Derecho Parlamentario, 16, 77-100. Recuperado de https://www.cortsualencianes.es/sites/default/ files/media/file_author/77laparidad.pdf

Nordstrom, B. (1990). Política y sistema social de género. En M. Judith Astelarra (Comp.). Participación política de las mujeres (pp. 23-38). Madrid: Siglo XXI de España - Centro de Investigaciones Sociológicas.

Perez Royo, J. (1999). Actas del coloquio "La ley electoral española y democracia paritaria". Madrid: Fundación Alternativas.

Renau i Manén, D. (1990). Mujer y política. En M. Judith Astelarra (Comp.). Participación política de las mujeres (pp. 235-240). Madrid: Siglo XXI de España - Centro de Investigaciones Sociológicas.
Rey Martínez, F. (1999). Cuotas electorales reservadas a mujeres y Constitución. Aequalitas: Revista jurídica de igualdad de oportunidades entre mujeres y hombres, 1, 52-59.

Rodrigues Canotilho, M. (2012). La igualdad de género en el Derecho Constitucional europeo. Revista de Derecho Constitucional Europeo, 17, 103-118. Recuperado de https://www.ugr.es/ redce/REDCE17/articulos/03_RODRIGUES.htm

Rubio Llorente, F. (1993). La forma del poder. Estudios sobre la Constitución. Madrid: Centro de Estudios Políticos y Constitucionales.

Ruiz Miguel, A. (1999). Paridad electoral y cuotas femeninas. Aequalitas: Revista juridica de igualdad de oportunidades entre mujeres y hombres, 1 , 44-51.

Sevilla Merino, J. (1997). La presencia de las mujeres en los Parlamentos: las Cortes Valencianas. Corts. Anuario de Derecho Parlamentario, 4, 369-411. Recuperado de https://www.cortsualencianes.es/ sites/default/files/media/file_author/369.pdf

Sevilla, J. (Dir.) (2006). Las mujeres parlamentarias en la legislatura Constituyente. Madrid: Congreso de los Diputados. Recuperado de

https://www.congreso.es/webpublica/estudios/ lasconstituyentes_Filmar.pdf

Subirats Martori, M. (1990). Problemas y reivindicaciones de las Mujeres: una cinta sin fin. En M. Judith Astelarra (Comp.). Participación política de las mujeres (pp. 117-131). Madrid: Siglo XXI de España - Centro de Investigaciones Sociológicas.

Vogel-Polsky, E. (1988). Las acciones positivas y los obstáculos constitucionales y legislativos que dificultan su realización en los Estados miembros del Consejo de Europa, CDEG. Estrasburgo, traducción al castellano realizada por el Instituto de la Mujer. Madrid. 1988. 


\section{ANEXO}

En este anexo podemos ver, en primer lugar, un cuadro con los resultados en las primeras elecciones de todas las comunidades autónomas para conocer el punto de partida.

A continuación, encontraremos la evolución de la presencia de mujeres en todos los parlamentos autonómicos a lo largo de diferentes citas electorales hasta la situación actual, haciendo también una comparativa por grupos parlamentarios entre la primera cita electoral y la última ${ }^{39}$.

\section{Resultados en las primeras elecciones autonómicas}

\begin{tabular}{|l|c|c|c|c|c|}
\hline Comunidad Autónoma & $\begin{array}{c}\text { Fecha } \\
\text { elecciones }\end{array}$ & Mujeres & \% Mujeres & Hombres & Total \\
\hline País Vasco & 09.03 .1980 & 4 & 6,67 & 56 & 60 \\
\hline Catalunya & 20.03 .1980 & 10 & 7,41 & 125 & 135 \\
\hline Galicia & 20.10 .1981 & 3 & 4,23 & 68 & 71 \\
\hline Andalucía & 23.05 .1982 & 6 & 5,50 & 103 & 109 \\
\hline Principado de Asturias & 08.05 .1983 & 4 & 8,89 & 41 & 45 \\
\hline Cantabria & 08.05 .1983 & 2 & 5,71 & 33 & 35 \\
\hline La Rioja & 08.05 .1983 & 3 & 8,57 & 32 & 35 \\
\hline Murcia & 08.05 .1983 & 1 & 2,33 & 42 & 43 \\
\hline Comunitat Valenciana & 08.03 .1983 & 5 & 5,62 & 84 & 89 \\
\hline Aragón & 08.05 .1983 & 3 & 4,54 & 63 & 66 \\
\hline Castilla-La Mancha & 08.05 .1983 & 1 & 2,72 & 43 & 44 \\
\hline Canarias & 08.05 .1983 & 1 & 1,67 & 59 & 60 \\
\hline Nauarra & 08.05 .1983 & 1 & 2,00 & 49 & 50 \\
\hline Extremadura & 08.05 .1982 & 3 & 4,62 & 62 & 65 \\
\hline Illes Balears & 08.05 .1983 & 3 & 5,56 & 51 & 54 \\
\hline Madrid & 08.05 .1983 & 12 & 12,77 & 82 & 94 \\
\hline Castilla y León & 08.05 .1983 & 2 & 2,38 & 82 & 84 \\
\hline & & & & & \\
\hline
\end{tabular}




\section{PARLAMENTO VASCO}

\begin{tabular}{|c|c|c|c|c|}
\hline $\begin{array}{c}\text { Fecha } \\
\text { elecciones }\end{array}$ & No mujeres & \% mujeres & № hombres & Total escaños \\
\hline 09.03 .1980 & 4 & 6,67 & 56 & 60 \\
\hline 25.10 .1998 & 22 & 29,33 & 53 & 75 \\
\hline 13.05 .2001 & 26 & 34,67 & 49 & 75 \\
\hline \multicolumn{5}{|c|}{ Ley 4/2005, de 18 de febrero, para la igualdad de mujeres y hombres } \\
\hline 17.04 .2005 & 39 & 52,00 & 36 & 75 \\
\hline Ley Orgánica 3/2007, de 22 de marzo, para la igualdad efectiva de mujeres y hombres \\
\hline 01.03 .2009 & 34 & 45,33 & 41 & 75 \\
\hline 21.10 .2012 & 37 & 49,33 & 38 & 75 \\
\hline 25.09 .2016 & 40 & 53,33 & 35 & 75 \\
\hline 12.07 .2020 & 38 & 50,67 & 37 & 75 \\
\hline
\end{tabular}

Número de mujeres y hombres por GGPP tras las elecciones del 9 de marzo de 1980:

\begin{tabular}{|l|c|c|c|}
\hline Grupo Parlamentario & № de mujeres & № de hombres & Total Grupo \\
\hline GP EA-NV & 4 & 21 & 25 \\
\hline GP HB & 0 & 11 & 11 \\
\hline GP ES-SV & 0 & 9 & 9 \\
\hline GP EE & 0 & 6 & 6 \\
\hline GP CV & 0 & 6 & 6 \\
\hline GP Mixto-AP & 0 & 2 & 2 \\
\hline GP Mixto-PC & 0 & 1 & 1 \\
\hline
\end{tabular}

Número de mujeres y hombres por GGPP tras las elecciones del 12 de julio de 2020:

\begin{tabular}{|l|c|c|c|}
\hline Grupo Parlamentario & № de mujeres & № de hombres & Total Grupo \\
\hline GP EA-NV & 16 & 15 & 31 \\
\hline GP EH Bildu & 12 & 9 & 21 \\
\hline GP SV-ES & 5 & 5 & 10 \\
\hline GP EP-IU & 2 & 4 & 6 \\
\hline Grupo VP-C & 2 & 4 & 6 \\
\hline GP Mixto (Vox) & 1 & 0 & 1 \\
\hline
\end{tabular}




\section{PARLAMENTO DE CATALUÑA}

\begin{tabular}{|c|c|c|c|c|}
\hline $\begin{array}{c}\text { Fecha } \\
\text { elecciones }\end{array}$ & № mujeres & $\%$ mujeres & № hombres & Total escaños \\
\hline 20.03 .1980 & 10 & 7,41 & 125 & 135 \\
\hline 16.11 .2003 & 32 & 23,70 & 103 & 135 \\
\hline 01.11 .2006 & 49 & 36,30 & 86 & 135 \\
\hline Ley Orgánica 3/2007, de 22 de marzo, para la igualdad efectiva de mujeres y hombres \\
\hline 28.11 .2010 & 56 & 41,50 & 79 & 135 \\
\hline 25.11 .2012 & 54 & 40,00 & 81 & 135 \\
\hline 27.09 .2015 & 53 & 39,26 & 82 & 135 \\
\hline 21.12 .2017 & 57 & 42,54 & 77 & 134 \\
\hline 14.02 .2021 & 66 & 48,80 & 69 & 135 \\
\hline
\end{tabular}

Número de mujeres y hombres por GGPP tras las elecciones del 20 de marzo de 1980:

\begin{tabular}{|l|c|c|c|}
\hline \multicolumn{1}{|c|}{ Grupo Parlamentario } & № de mujeres & № de hombres & Total Grupo \\
\hline GP Convergència i Unió & 4 & 39 & 43 \\
\hline GP PSC-PSOE & 2 & 31 & 33 \\
\hline GP PSUC & 3 & 20 & 23 \\
\hline GP UCD & 1 & 17 & 18 \\
\hline GP ERC & 0 & 14 & 14 \\
\hline GP PS Andaluz & 0 & 2 & 2 \\
\hline GP Mixto & 0 & 2 & 2 \\
\hline
\end{tabular}

Número de mujeres y hombres por GGPP tras las elecciones del 14 de febrero de 2021:

\begin{tabular}{|l|c|c|c|}
\multicolumn{1}{|c|}{ Grupo Parlamentario } & № de mujeres & № de hombres & Total Grupo \\
\hline GP Socialista i Units per Auançar & 17 & 16 & 33 \\
\hline GP Esquerra Republicana & 17 & 16 & 33 \\
\hline GP Junts x Cat & 17 & 15 & 32 \\
\hline GP Vox en Catalunya & 3 & 8 & 11 \\
\hline GP Candidatura Unitat Popular & 5 & 4 & 9 \\
\hline GP En Comú Podem & 3 & 5 & 8 \\
\hline GP Ciutadans & 2 & 4 & 6 \\
\hline Grup Mixt (PP) & 2 & 1 & 3 \\
\hline
\end{tabular}


PARLAMENTO DE GALICIA

\begin{tabular}{|c|c|c|c|c|}
\hline $\begin{array}{c}\text { Fecha } \\
\text { elecciones }\end{array}$ & № mujeres & \% mujeres & № hombres & Total escaños \\
\hline 20.10 .1981 & 3 & 4,23 & 68 & 71 \\
\hline 19.10 .1997 & 13 & 16,67 & 65 & 78 \\
\hline 21.10 .2001 & 25 & 33,33 & 50 & 75 \\
\hline 19.06 .2005 & 25 & 33,33 & 50 & 75 \\
\hline \multicolumn{2}{|c|}{ Ley Orgánica 3/2007, de 22 de marzo, para la igualdad efectiva de mujeres y hombres } \\
\hline 01.03 .2009 & 30 & 40,00 & 45 & 75 \\
\hline 21.10 .2012 & 30 & 40,00 & 45 & 75 \\
\hline 25.09 .2016 & 34 & 45,33 & 41 & 75 \\
\hline
\end{tabular}

Número de mujeres y hombres por GGPP tras las elecciones del 20 de octubre de 1981:

\begin{tabular}{|l|c|c|c|}
\hline \multicolumn{1}{|c|}{ Grupo Parlamentario } & № de mujeres & № de hombres & Total Grupo \\
\hline GP AP & 1 & 25 & 26 \\
\hline GP UCD & 2 & 22 & 24 \\
\hline GP PSG-PSOE & 0 & 16 & 16 \\
\hline GP BNPG-PSG & 0 & 3 & 3 \\
\hline GP EG & 0 & 1 & 1 \\
\hline GP PCG & 0 & 1 & 1 \\
\hline
\end{tabular}

Número de mujeres y hombres por GGPP tras las elecciones del 25 de septiembre de 2016:

\begin{tabular}{|l|c|c|c|}
\hline \multicolumn{1}{|c|}{ Grupo Parlamentario } & № de mujeres & № de hombres & Total Grupo \\
\hline GP Popular de Galicia & 16 & 23 & 41 \\
\hline GP dos Socialistas de Galicia & 9 & 5 & 14 \\
\hline GP Alternativa Galega Esquerda & 6 & 3 & 9 \\
\hline GP Bloque Nacionalista Galego & 4 & 2 & 6 \\
\hline GP Mixto & 2 & 3 & 5 \\
\hline
\end{tabular}




\section{PARLAMENTO DE ANDALUCÍA}

\begin{tabular}{|l|c|c|c|c|}
\hline $\begin{array}{c}\text { Fecha } \\
\text { elecciones }\end{array}$ & № mujeres & $\%$ mujeres & № hombres & Total escaños \\
\hline 23.05 .1982 & 6 & 5,50 & 103 & 109 \\
\hline 12.03 .2000 & 38 & 34,86 & 71 & 109 \\
\hline 14.03 .2004 & 43 & 39,45 & 66 & 109 \\
\hline \multicolumn{5}{|c|}{ Ley 5/2005, de 8 de abril, por la que se modifica la Ley 1/1986, de 2 de enero, } \\
Electoral de Andalucía \\
\hline \multicolumn{5}{|c|}{ Ley Orgánica 3/2007, de 22 de marzo, para la igualdad efectiva de mujeres y hombres } \\
\hline 09.03.2008 & 50 & 45,87 & 59 & 109 \\
\hline 25.03 .2012 & 52 & 47,71 & 57 & 109 \\
\hline 22.03 .2015 & 54 & 49,54 & 55 & 109 \\
\hline 02.12 .2018 & 54 & 49,54 & 55 & 109 \\
\hline
\end{tabular}

Número de mujeres y hombres por GGPP tras las elecciones del 23 de mayo de 1982:

\begin{tabular}{|l|c|c|c|}
\hline \multicolumn{1}{|c|}{ Grupo Parlamentario } & № de mujeres & № de hombres & Total Grupo \\
\hline GP PSOE-A & 4 & 62 & 66 \\
\hline GP AP & 1 & 16 & 17 \\
\hline GP UCD & 1 & 14 & 15 \\
\hline GP PCA-PCE & 0 & 8 & 8 \\
\hline GP PSA & 0 & 3 & 3 \\
\hline
\end{tabular}

Número de mujeres y hombres por GGPP tras las elecciones del 2 de diciembre de 2018:

\begin{tabular}{|l|c|c|c|}
\hline \multicolumn{1}{|c|}{ Grupo Parlamentario } & № de mujeres & № de hombres & Total Grupo \\
\hline GP Socialista Andaluz & 17 & 16 & 33 \\
\hline GP Popular Andaluz & 15 & 11 & 26 \\
\hline GP Ciudadanos & 10 & 11 & 21 \\
\hline GP Adelante Andalucía & 9 & 8 & 17 \\
\hline GP Vox en Andalucía & 4 & 8 & 12 \\
\hline
\end{tabular}


JUNTA GENERAL DEL PRINCIPADO DE ASTURIAS

\begin{tabular}{|c|c|c|c|c|}
\hline $\begin{array}{c}\text { Fecha } \\
\text { elecciones }\end{array}$ & № mujeres & $\%$ mujeres & № hombres & Total escaños \\
\hline 08.05 .1983 & 4 & 8,89 & 41 & 45 \\
\hline 25.05 .2003 & 14 & 31,11 & 31 & 45 \\
\hline \multicolumn{5}{|c|}{ Ley Orgánica 3/2007, de 22 de marzo, para la igualdad efectiva de mujeres y hombres } \\
\hline 27.05 .2007 & 15 & 33,33 & 30 & 45 \\
\hline \multicolumn{5}{|c|}{ Ley del Principado de Asturias 2/2011, de 11 de marzo, para la igualdad de mujeres y } \\
hombres y la erradicación de la violencia de género \\
\hline 22.05 .2011 & 19 & 42,22 & 26 & 45 \\
\hline 24.05 .2015 & 22 & 48,89 & 23 & 45 \\
\hline 26.05 .2019 & 22 & 47,83 & 24 & 46 \\
\hline
\end{tabular}

Número de mujeres y hombres por GGPP tras las elecciones del 8 de mayo de 1983:

\begin{tabular}{|l|c|c|c|}
\hline \multicolumn{1}{|c|}{ Grupo Parlamentario } & № de mujeres & № de hombres & Total Grupo \\
\hline GP Socialista & 2 & 24 & 26 \\
\hline GP AP-PDP-UL & 1 & 13 & 14 \\
\hline GP PCA-PCE & 1 & 4 & 5 \\
\hline
\end{tabular}

Número de mujeres y hombres por GGPP tras las elecciones del 26 de mayo de 2019:

\begin{tabular}{|l|c|c|c|}
\hline \multicolumn{1}{|c|}{ Grupo Parlamentario } & № de mujeres & № de hombres & Total Grupo \\
\hline GP Socialista & 10 & 10 & 20 \\
\hline GP Popular & 5 & 5 & 10 \\
\hline GP Ciudadanos & 2 & 3 & 5 \\
\hline GP Podemos & 2 & 2 & 4 \\
\hline GP IU-IAS & 1 & 1 & 2 \\
\hline GP FAC & 0 & 2 & 2 \\
\hline GP Vox & 1 & 1 & 2 \\
\hline
\end{tabular}




\section{PARLAMENTO DE CANTABRIA}

\begin{tabular}{|c|c|c|c|c|}
\hline $\begin{array}{c}\text { Fecha } \\
\text { elecciones }\end{array}$ & No mujeres & \% mujeres & No hombres & Total escaños \\
\hline 08.05 .1983 & 2 & 5,71 & 33 & 35 \\
\hline 25.05 .2003 & 16 & 41,03 & 23 & 39 \\
\hline Ley Orgánica $3 / 2007$, de 22 de marzo, para la igualdad efectiva de mujeres y hombres \\
\hline 27.05 .2007 & 17 & 40,48 & 25 & 42 \\
\hline 22.05 .2011 & 17 & 43,59 & 22 & 39 \\
\hline 24.05 .2015 & 14 & 38,89 & 22 & 36 \\
\hline Ley de Cantabria $2 / 2019$, de 7 de marzo, para la igualdad efectiva entre hombres y mujeres \\
\hline \multicolumn{5}{|c|}{15} \\
\hline
\end{tabular}

Número de mujeres y hombres por GGPP tras las elecciones del 8 de mayo de 1983:

\begin{tabular}{|l|c|c|c|}
\hline \multicolumn{1}{|c|}{ Grupo Parlamentario } & № de mujeres & № de hombres & Total Grupo \\
\hline GP AP-PDP-UL & 1 & 17 & 18 \\
\hline GP PSOE & 1 & 14 & 15 \\
\hline GP PRC & 0 & 2 & 2 \\
\hline
\end{tabular}

Número de mujeres y hombres por GGPP tras las elecciones del 26 de mayo de 2019:

\begin{tabular}{|l|c|c|c|}
\hline \multicolumn{1}{|c|}{ Grupo Parlamentario } & No de mujeres & No de hombres & Total Grupo \\
\hline GP Regionalista (PRC) & 7 & 7 & 14 \\
\hline GP Popular & 6 & 3 & 9 \\
\hline GP Socialista & 3 & 4 & 7 \\
\hline GP Ciudadanos & 2 & 1 & 3 \\
\hline GP Mixto (Vox) & 0 & 2 & 2 \\
\hline
\end{tabular}


PARLAMENTO DE LA RIOJA

\begin{tabular}{|l|c|c|c|c|}
\hline $\begin{array}{c}\text { Fecha } \\
\text { elecciones }\end{array}$ & № mujeres & $\%$ mujeres & № hombres & Total escaños \\
\hline 08.05 .1983 & 3 & 8,57 & 32 & 35 \\
\hline 25.05 .2003 & 13 & 39,39 & 20 & 33 \\
\hline \multicolumn{5}{|c|}{ Ley Orgánica 3/2007, de 22 de marzo, para la igualdad efectiva de mujeres y hombres } \\
\hline 27.05 .2007 & 13 & 39,39 & 20 & 33 \\
\hline \multicolumn{5}{|c|}{ Ley 3/2011, de 1 de marzo, de prevención, protección y coordinación institucional en } \\
materia de violencia en La Rioja \\
\hline 22.05 .2011 & 13 & 39,39 & 20 & 33 \\
\hline 24.05 .2015 & 15 & 45,45 & 18 & 33 \\
\hline 26.05 .2019 & 16 & 48,48 & 17 & 33 \\
\hline
\end{tabular}

Número de mujeres y hombres por GGPP constituido tras las elecciones del 8 de mayo de 1983:

\begin{tabular}{|l|c|c|c|}
\multicolumn{1}{|c|}{ Grupo Parlamentario } & № de mujeres & № de hombres & Total Grupo \\
\hline GP PSOE & 1 & 17 & 18 \\
\hline GP AP-PDP-UL & 2 & 13 & 15 \\
\hline GP PRP & 0 & 2 & 2 \\
\hline
\end{tabular}

Número de mujeres y hombres por GGPP constituido tras las elecciones del 26 de mayo de 2019:

\begin{tabular}{|l|c|c|c|}
\hline \multicolumn{1}{|c|}{ Grupo Parlamentario } & № de mujeres & № de hombres & Total Grupo \\
\hline GP Socialista & 8 & 7 & 15 \\
\hline GP Popular & 4 & 8 & 12 \\
\hline GP Ciudadanos & 2 & 2 & 4 \\
\hline GP Mixto & 2 & 0 & 2 \\
\hline
\end{tabular}




\section{ASAMBLEA REGIONAL DE MURCIA}

\begin{tabular}{|l|c|c|c|c|}
\begin{tabular}{|} 
Fecha \\
elecciones
\end{tabular} & No mujeres & \% mujeres & No hombres & Total escaños \\
\hline 08.05 .1983 & 1 & 2,33 & 42 & 43 \\
\hline 25.05 .2003 & 14 & 31,11 & 31 & 45 \\
\hline \multicolumn{5}{|c|}{ Ley 7/2007, de 4 de abril, para la lgualdad entre Mujeres y Hombres, y de Protección } \\
contra la Violencia de Género en la Región de Murcia
\end{tabular}

Número de mujeres y hombres por GGPPP tras las elecciones del 8 de mayo de 1983:

\begin{tabular}{|l|c|c|c|}
\hline \multicolumn{1}{|c|}{ Grupo Parlamentario } & № de mujeres & No de hombres & Total Grupo \\
\hline GP PSRM-PSOE & 1 & 25 & 26 \\
\hline GP AP-PDP-UL & 0 & 16 & 16 \\
\hline GP PCE & 0 & 1 & 1 \\
\hline
\end{tabular}

Número de mujeres y hombres por GGPP tras las elecciones del 26 de mayo de 2019:

\begin{tabular}{|l|c|c|c|}
\hline \multicolumn{1}{|c|}{ Grupo Parlamentario } & № de mujeres & № de hombres & Total Grupo \\
\hline GP Socialista & 8 & 9 & 17 \\
\hline GP Popular & 7 & 8 & 15 \\
\hline GP Vox & 1 & 3 & 4 \\
\hline GP Ciudadanos & 3 & 3 & 6 \\
\hline GP Podemos & 1 & 1 & 2 \\
\hline
\end{tabular}


CORTS VALENCIANES

\begin{tabular}{|l|c|c|c|c|}
\hline $\begin{array}{c}\text { Fecha } \\
\text { elecciones }\end{array}$ & No mujeres & \% mujeres & No hombres & Total escaños \\
\hline 08.03 .1983 & 5 & 5,62 & 84 & 89 \\
\hline Ley 9/2003, de 2 de abril, de la Generalitat, para la lgualdad entre Mujeres y Hombres \\
\hline 25.05 .2003 & 38 & 42,70 & 51 & 89 \\
\hline Ley Orgánica 3/2007, de 22 de marzo, para la igualdad efectiva de mujeres y hombres \\
\hline 27.05 .2007 & 44 & 44,44 & & 99 \\
\hline 22.05 .2011 & 39 & 39,39 & 60 & 99 \\
\hline 24.05 .2015 & 45 & 45,45 & 54 & 99 \\
\hline 28.04 .2019 & 46 & 46,46 & 53 & 99 \\
\hline
\end{tabular}

Número de mujeres y hombres por GGPP tras las elecciones del 8 de mayo de 1983:

\begin{tabular}{|l|c|c|c|}
\hline \multicolumn{1}{|c|}{ Grupo Parlamentario } & № de mujeres & № de hombres & Total Grupo \\
\hline GP Socialista & 3 & 48 & 51 \\
\hline GP Popular & 2 & 30 & 32 \\
\hline GP Comunista & 0 & 6 & 6 \\
\hline
\end{tabular}

Número de mujeres y hombres por GGPP tras las elecciones del 28 de abril de 2019:

\begin{tabular}{|l|c|c|c|}
\hline \multicolumn{1}{|c|}{ Grupo Parlamentario } & № de mujeres & № de hombres & Total Grupo \\
\hline GP Socialista & 13 & 14 & 27 \\
\hline GP Popular & 7 & 12 & 19 \\
\hline GP Ciudadanos & 8 & 10 & 18 \\
\hline GP Compromís & 8 & 9 & 17 \\
\hline GP Vox Comunidad Valenciana & 4 & 6 & 10 \\
\hline GP Unides Podem & 6 & 2 & 8 \\
\hline
\end{tabular}




\section{CORTES DE ARAGÓN}

\begin{tabular}{|l|c|c|c|c|}
\hline $\begin{array}{c}\text { Fecha } \\
\text { elecciones }\end{array}$ & № mujeres & \% mujeres & № hombres & Total escaños \\
\hline 08.05 .1983 & 3 & 4,54 & 63 & 66 \\
\hline 25.05 .2003 & 21 & 31,34 & 46 & 67 \\
\hline Ley Orgánica 3/2007, de 22 de marzo, para la igualdad efectiva de mujeres y hombres \\
\hline 27.05 .2007 & 24 & 35,82 & 43 & 67 \\
\hline 22.05 .2011 & 22 & 32,84 & 45 & 67 \\
\hline 24.05 .2015 & 32 & 47,76 & 35 & 67 \\
\hline 26.05 .2019 & 32 & 47,76 & 35 & 67 \\
\hline
\end{tabular}

Número de mujeres y hombres por GGPP tras las elecciones del 8 de mayo de 1983:

\begin{tabular}{|l|c|c|c|}
\hline \multicolumn{1}{|c|}{ Grupo Parlamentario } & № de mujeres & No de hombres & Total Grupo \\
\hline GP Socialista & 3 & 30 & 33 \\
\hline GP Popular & 0 & 12 & 12 \\
\hline GP PAR & 0 & 12 & 12 \\
\hline GP Mixto & 0 & 9 & 9 \\
\hline
\end{tabular}

Número de mujeres y hombres por GGPP tras las elecciones del 26 de mayo de 2019:

\begin{tabular}{|l|c|c|c|}
\hline \multicolumn{1}{|c|}{ Grupo Parlamentario } & No de mujeres & No de hombres & Total Grupo \\
\hline GP Socialista & 12 & 12 & 24 \\
\hline GP Popular & 7 & 9 & 16 \\
\hline GP Ciudadanos & 6 & 6 & 12 \\
\hline GP Podemos-Equo & 3 & 2 & 5 \\
\hline GP Chunta Aragonesista & 1 & 2 & 3 \\
\hline GP Vox en Aragón & 1 & 2 & 3 \\
\hline GP Aragonés & 1 & 2 & 3 \\
\hline GP Mixto (IU) & 0 & 1 & 1 \\
\hline
\end{tabular}


CORTES DE CASTILLA-LA MANCHA

\begin{tabular}{|c|c|c|c|c|}
\hline $\begin{array}{c}\text { Fecha } \\
\text { elecciones }\end{array}$ & No mujeres & $\%$ mujeres & № hombres & Total escaños \\
\hline 08.05 .1983 & 1 & 2,72 & 43 & 44 \\
\hline \multicolumn{5}{|c|}{ Ley 11/2002, de 27 de junio, de modificación de la Ley 5/1986, de 23 de diciembre, } \\
Electoral de Castilla-La Mancha \\
\hline 25.05 .2003 & 25 & 53,19 & 22 & 47 \\
\hline Ley Orgánica 3/2007, de 22 de marzo, para la igualdad efectiva de mujeres y hombres \\
\hline 27.05 .2007 & 25 & 53,19 & 22 & 47 \\
\hline 22.05 .2011 & 23 & 46,94 & 26 & 49 \\
\hline 24.05 .2015 & 14 & 42,42 & 19 & 33 \\
\hline 26.05 .2019 & 15 & 45,45 & 18 & 33 \\
\hline
\end{tabular}

Número de mujeres y hombres por GGPP tras las elecciones del 8 de mayo de 1983:

\begin{tabular}{|l|c|c|c|}
\hline \multicolumn{1}{|c|}{ Grupo Parlamentario } & № de mujeres & № de hombres & Total Grupo \\
\hline GP Socialista & 0 & 23 & 23 \\
\hline GP Popular & 1 & 20 & 21 \\
\hline
\end{tabular}

Número de mujeres y hombres por GGPP tras las elecciones del 26 de mayo de 2019:

\begin{tabular}{|l|c|c|c|}
\hline \multicolumn{1}{|c|}{ Grupo Parlamentario } & № de mujeres & № de hombres & Total Grupo \\
\hline GP Socialista & $\mathbf{8}$ & 11 & 19 \\
\hline GP Popular & 5 & 5 & 10 \\
\hline GP Ciudadanos & 2 & 2 & 4 \\
\hline
\end{tabular}




\section{PARLAMENTO DE CANARIAS}

\begin{tabular}{|l|c|c|c|c|}
\hline $\begin{array}{c}\text { Fecha } \\
\text { elecciones }\end{array}$ & № mujeres & $\%$ mujeres & № hombres & Total escaños \\
\hline 08.05 .1983 & 1 & 1,67 & 59 & 60 \\
\hline 25.05 .2003 & 21 & 35,00 & 39 & 60 \\
\hline \multicolumn{2}{|c|}{ Ley Orgánica 3/2007, de 22 de marzo, para la igualdad efectiva de mujeres y hombres } \\
\hline 27.05 .2007 & 24 & 40,00 & 36 & 60 \\
\hline 22.05 .2011 & 22 & 36,67 & 38 & 60 \\
\hline 24.05 .2015 & 32 & 53,33 & 28 & 60 \\
\hline 26.05 .2019 & 31 & 44,29 & 39 & 70 \\
\hline \multicolumn{5}{|c|}{ Ley $1 / 2010$, de 26 de febrero, canaria de igualdad entre mujeres y hombres } \\
\hline
\end{tabular}

Número de mujeres y hombres por GGPP tras las elecciones del 8 de mayo de 1983:

\begin{tabular}{|l|c|c|c|}
\multicolumn{1}{r|}{ Grupo Parlamentario } & № de mujeres & № de hombres & Total Grupo \\
\hline GP PSOE & 1 & 26 & 27 \\
\hline GP AP-PDP-UL & 0 & 17 & 17 \\
\hline GP CDS & 0 & 6 & 6 \\
\hline GP AM & 0 & 3 & 3 \\
\hline GP UPC-AC & 0 & 2 & 2 \\
\hline GP AGI & 0 & 2 & 2 \\
\hline GP CCNC & 0 & 1 & 1 \\
\hline GP PCC-PCE & 0 & 1 & 1 \\
\hline GP AHI & 0 & 1 & 1 \\
\hline
\end{tabular}

Número de mujeres y hombres por GGPP tras las elecciones del 26 de mayo de 2019:

\begin{tabular}{|l|c|c|c|}
\hline \multicolumn{1}{|c|}{ Grupo Parlamentario } & № de mujeres & № de hombres & Total Grupo \\
\hline GP Socialista Canario & 12 & 13 & 25 \\
\hline $\begin{array}{l}\text { GP Nacionalista Canario } \\
\text { (CC-PNC-AHI) }\end{array}$ & 8 & 12 & 20 \\
\hline GP Popular & 7 & 4 & 11 \\
\hline GP Nueva Canarias (NC) & 3 & 2 & 5 \\
\hline GP Sí Podemos Canarias & 2 & 2 & 4 \\
\hline $\begin{array}{l}\text { GP Agrupación Socialista Gomera } \\
\text { (ASG) }\end{array}$ & 1 & 2 & 3 \\
\hline GP Mixto & 1 & 1 & 2 \\
\hline
\end{tabular}


PARLAMENTO DE NAVARRA

\begin{tabular}{|c|c|c|c|c|}
\hline $\begin{array}{c}\text { Fecha } \\
\text { elecciones }\end{array}$ & № mujeres & $\%$ mujeres & № hombres & Total escaños \\
\hline 08.05 .1983 & 1 & 2,00 & 49 & 50 \\
\hline 25.05 .2003 & 16 & 32,00 & 34 & 50 \\
\hline Ley Orgánica 3/2007, de 22 de marzo, para la igualdad efectiva de mujeres y hombres \\
\hline 27.05 .2007 & 19 & 38,00 & 31 & 50 \\
\hline 22.05 .2011 & 17 & 34,00 & 33 & 50 \\
\hline 24.05 .2015 & 24 & 48,00 & 26 & 50 \\
\hline \multicolumn{5}{|c|}{ Ley Foral 17/2019, de 4 de abril, de lgualdad entre Mujeres y Hombres } \\
\hline 26.05 .2019 & 25 & 50,00 & 25 & 50 \\
\hline
\end{tabular}

Número de mujeres y hombres por GGPP tras las elecciones del 8 de mayo de 1983 :

\begin{tabular}{|l|c|c|c|}
\multicolumn{1}{|c|}{ Grupo Parlamentario } & № de mujeres & № de hombres & Total Grupo \\
\hline GP PSN-PSOE & 1 & 19 & 20 \\
\hline GP UPN & 0 & 13 & 13 \\
\hline GP AP-PDP-UL & 0 & 8 & 8 \\
\hline GP HB & 0 & 6 & 6 \\
\hline GP PNV & 0 & 3 & 3 \\
\hline
\end{tabular}

Número de mujeres y hombres por GGPP tras las elecciones del 26 de mayo de 2019:

\begin{tabular}{|l|c|c|c|}
\hline \multicolumn{1}{|c|}{ Grupo Parlamentario } & № de mujeres & № de hombres & Total Grupo \\
\hline GP Navarra Suma & 8 & 12 & 20 \\
\hline GP Socialista de Navarra & 7 & 4 & 11 \\
\hline GP Geroa Bai & 5 & 4 & 9 \\
\hline GP EH Bildu Nafarroa & 4 & 3 & 7 \\
\hline GP Adal Dugu Navarra Podemos & 1 & 1 & 2 \\
\hline GP Mixto-Izquierda-Ezkerra & 1 & 0 & 1 \\
\hline
\end{tabular}




\section{ASAMBLEA DE EXTREMADURA}

\begin{tabular}{|l|c|c|c|c|}
\hline $\begin{array}{c}\text { Fecha } \\
\text { elecciones }\end{array}$ & No mujeres & \% mujeres & No hombres & Total escaños \\
\hline 08.05 .1982 & 3 & 4,62 & 62 & 65 \\
\hline 25.05 .2003 & 24 & 36,92 & 41 & 65 \\
\hline Ley Orgánica 3/2007, de 22 de marzo, para la igualdad efectiva de mujeres y hombres \\
\hline 27.05 .2007 & 26 & 40,00 & 39 & 65 \\
\hline 22.05 .2011 & 26 & 40,00 & 39 & 65 \\
\hline 24.05 .2015 & 31 & 47,62 & 34 & 65 \\
\hline 26.05 .2019 & 29 & 44,62 & 36 & 65 \\
\hline
\end{tabular}

Número de mujeres y hombres por GGPP tras las elecciones del 8 de mayo de 1983:

\begin{tabular}{|l|c|c|c|}
\hline \multicolumn{1}{|c|}{ Grupo Parlamentario } & № de mujeres & № de hombres & Total Grupo \\
\hline GP PSOE & 2 & 33 & 35 \\
\hline GP AP-PDP-UL & 0 & 20 & 20 \\
\hline GP Extremadura Unida & 1 & 5 & 6 \\
\hline GP PCE & 0 & 4 & 4 \\
\hline
\end{tabular}

Número de mujeres y hombres por GGPP tras las elecciones del 26 de mayo de 2019:

\begin{tabular}{|l|c|c|c|}
\hline \multicolumn{1}{|c|}{ Grupo Parlamentario } & No de mujeres & № de hombres & Total Grupo \\
\hline GP Socialista & 17 & 17 & 34 \\
\hline GP Popular & 11 & 8 & 20 \\
\hline GP Ciudadanos & 5 & 2 & 7 \\
\hline $\begin{array}{l}\text { GP Unidas por Extremadura } \\
\text { (Podemos-IU-Extremeños-Equo) }\end{array}$ & 2 & 2 & 4 \\
\hline
\end{tabular}




\section{PARLAMENTO DE LAS ISLAS BALEARES}

\begin{tabular}{|c|c|c|c|c|}
\hline $\begin{array}{c}\text { Fecha } \\
\text { elecciones }\end{array}$ & № mujeres & $\%$ mujeres & № hombres & Total escaños \\
\hline 08.05 .1983 & 3 & 5,56 & 51 & 54 \\
\hline \multicolumn{5}{|c|}{$\begin{array}{c}\text { Ley 6/2002, de } 21 \text { de junio, de modificación de la Ley 8/1986, electoral de la Comunidad } \\
\text { Autónoma de las Illes Balears }\end{array}$} \\
\hline 05.05 .2003 & 21 & 37,50 & 35 & 56 \\
\hline \multicolumn{5}{|c|}{ Ley Orgánica 3/2007, de 22 de marzo, para la igualdad efectiva de mujeres y hombres } \\
\hline 27.05.2007 & 29 & 49,15 & 30 & 59 \\
\hline 22.05 .2011 & 27 & 45,76 & 32 & 59 \\
\hline 24.05 .2015 & 28 & 47,46 & 31 & 59 \\
\hline 26.05 .2019 & 28 & 47,46 & 31 & 59 \\
\hline
\end{tabular}

Número de mujeres y hombres por GGPP tras las elecciones del 8 de mayo de 1983:

\begin{tabular}{|l|c|c|c|}
\hline \multicolumn{1}{|c|}{ Grupo Parlamentario } & No de mujeres & № de hombres & Total Grupo \\
\hline GP AP-PDP-UL & 1 & 20 & 21 \\
\hline GP PSOE & 1 & 20 & 21 \\
\hline GP UM & 1 & 5 & 6 \\
\hline GP PS Mallorca & 0 & 2 & 2 \\
\hline GP PS Menorca & 0 & 2 & 2 \\
\hline GP PDL & 0 & 1 & 1 \\
\hline GP CIM & 0 & 1 & 1 \\
\hline
\end{tabular}

Número de mujeres y hombres por GGPP tras las elecciones del 26 de mayo de 2019:

\begin{tabular}{|l|c|c|c|}
\hline \multicolumn{1}{|c|}{ Grupo Parlamentario } & No de mujeres & № de hombres & Total Grupo \\
\hline GP Socialista & 10 & 9 & 19 \\
\hline GP Popular & 7 & 9 & 16 \\
\hline GP Unidas Podemos & 3 & 3 & 6 \\
\hline GP Ciudadanos & 1 & 2 & 5 \\
\hline GP Més per Mallorca & 2 & 2 & 4 \\
\hline GP Vox-Actúa Baleares & 1 & 2 & 3 \\
\hline $\begin{array}{l}\text { GP El Pi-Proposta per les Illes } \\
\text { Balears }\end{array}$ & 1 & 1 & 3 \\
\hline Grupo Mixto & 2 & 4 & 3 \\
\hline
\end{tabular}




\section{ASAMBLEA DE LA COMUNIDAD DE MADRID}

\begin{tabular}{|l|c|c|c|c|}
\hline $\begin{array}{c}\text { Fecha } \\
\text { elecciones }\end{array}$ & No mujeres & \% mujeres & No hombres & Total escaños \\
\hline 08.05 .1983 & 12 & 12,77 & 82 & 94 \\
\hline 13.06 .1999 & 33 & 32,35 & 69 & 102 \\
\hline 25.05 .2003 & - & - & - & - \\
\hline $\begin{array}{l}26.10 .2003 \\
\text { (Repetición } \\
\text { elecciones) }\end{array}$ & 42 & 37,84 & 69 & 111 \\
\hline Ley Orgánica $3 / 2007$, de 22 de marzo, para la igualdad efectiva de mujeres y hombres \\
\hline 27.05 .2007 & 51 & 42,50 & 69 & 120 \\
\hline 22.05 .2011 & 57 & 44,19 & 72 & 129 \\
\hline 24.05 .2015 & 55 & 42,64 & 74 & 129 \\
\hline 26.05 .2019 & 61 & 46,21 & 71 & 136 \\
\hline 04.05 .2021 & 65 & 47,79 & 71 & \\
\hline
\end{tabular}

Número de mujeres y hombres por GGPP tras las elecciones del 8 de mayo de 1983:

\begin{tabular}{|l|c|c|c|}
\hline \multicolumn{1}{|c|}{ Grupo Parlamentario } & № de mujeres & No de hombres & Total Grupo \\
\hline GP PSOE & 7 & 44 & 51 \\
\hline GP AP-PDP-UL & 4 & 30 & 34 \\
\hline GP PCE & 1 & 8 & 9 \\
\hline
\end{tabular}

Número de mujeres y hombres por GGPP tras las elecciones del 4 de mayo de 2021:

\begin{tabular}{|l|c|c|c|}
\hline \multicolumn{1}{|c|}{ Grupo Parlamentario } & № de mujeres & № de hombres & Total Grupo \\
\hline GP Popular & 29 & 36 & 65 \\
\hline GP Más Madrid & 12 & 12 & 24 \\
\hline GP Socialista & 14 & 10 & 24 \\
\hline GP Vox & 4 & 9 & 13 \\
\hline GP Unidas Podemos & 6 & 4 & 10 \\
\hline
\end{tabular}




\section{CORTES DE CASTILLA Y LEÓN}

\begin{tabular}{|l|c|c|c|c|}
$\begin{array}{c}\text { Fecha } \\
\text { elecciones }\end{array}$ & No mujeres & \% mujeres & № hombres & Total escaños \\
\hline 08.05 .1983 & 2 & 2,38 & 82 & 84 \\
\hline 25.05 .2003 & 27 & 36,00 & 48 & 75 \\
\hline \multicolumn{5}{|c|}{ Ley 1/2003, de 7 de marzo, de lgualdad de Oportunidades entre Mujeres y Hombres en } \\
Castilla y León \\
\hline \multicolumn{5}{|c|}{ Ley Orgánica 3/2007, de 22 de marzo, para la igualdad efectiva de mujeres y hombres } \\
\hline 27.05 .2007 & 36 & 43,37 & 47 & 83 \\
\hline 22.05 .2011 & 56 & 66,67 & 28 & 84 \\
\hline 24.05 .2015 & 35 & 41,67 & 49 & 84 \\
\hline 26.05 .2019 & 35 & 43,21 & 46 & 81 \\
\hline
\end{tabular}

Número de mujeres y hombres por GGPP tras las elecciones del 8 de mayo de 1983:

\begin{tabular}{|l|c|c|c|}
\multicolumn{1}{|c|}{ Grupo Parlamentario } & № de mujeres & № de hombres & Total Grupo \\
\hline GP PSOE & 2 & 40 & 42 \\
\hline GP AP-PDP-UL & 0 & 39 & 39 \\
\hline GP CDS & 0 & 2 & 2 \\
\hline GP PDL & 0 & 1 & 1 \\
\hline
\end{tabular}

Número de mujeres y hombres GGPP tras las elecciones del 26 de mayo de 2019:

\begin{tabular}{|l|c|c|c|}
\hline \multicolumn{1}{|c|}{ Grupo Parlamentario } & № de mujeres & № de hombres & Total Grupo \\
\hline GP Socialista & 17 & 18 & 35 \\
\hline GP Popular & 11 & 18 & 29 \\
\hline GP Ciudadanos & 6 & 6 & 12 \\
\hline GP Mixto & 1 & 4 & 5 \\
\hline
\end{tabular}




\section{ASAMBLEA DE LA CIUDAD AUTÓNOMA DE CEUTA}

\begin{tabular}{|c|c|c|c|c|}
\hline $\begin{array}{c}\text { Fecha } \\
\text { elecciones }\end{array}$ & № mujeres & $\%$ mujeres & № hombres & Total escaños \\
\hline 25.05 .2003 & 8 & 33,33 & 16 & 24 \\
\hline \multicolumn{4}{|c|}{ Ley Orgánica 3/2007, de 22 de marzo, para la igualdad efectiva de mujeres y hombres } \\
\hline 27.05 .2007 & 10 & 40,00 & 15 & 25 \\
\hline 22.05 .2011 & 10 & 40,00 & 15 & 25 \\
\hline 24.05 .2015 & 10 & 40,00 & 15 & 25 \\
\hline 26.05 .2019 & 11 & 44,00 & 14 & 25 \\
\hline
\end{tabular}

Número de mujeres y hombres por GGPP tras las elecciones del 26 de mayo de 2019:

\begin{tabular}{|l|c|c|c|}
\hline \multicolumn{1}{|c|}{ Grupo Parlamentario } & № de mujeres & № de hombres & Total Grupo \\
\hline GP Popular & 4 & 5 & 9 \\
\hline GP Socialista & 3 & 4 & 7 \\
\hline GP VOX & 2 & 4 & 6 \\
\hline $\begin{array}{l}\text { GP Mouimiento por la Dignidad y } \\
\text { la Ciudadanía }\end{array}$ & 1 & 1 & 2 \\
\hline GP Coalición Caballas & 0 & 1 & 1 \\
\hline
\end{tabular}




\section{ASAMBLEA DE LA CIUDAD AUTÓNOMA DE MELILLA}

\begin{tabular}{|l|c|c|c|c|}
\hline $\begin{array}{c}\text { Fecha } \\
\text { elecciones }\end{array}$ & № mujeres & $\%$ mujeres & № hombres & Total escaños \\
\hline 25.05 .2003 & 8 & 32,00 & 17 & 25 \\
\hline \multicolumn{4}{|c|}{ Ley Orgánica 3/2007, de 22 de marzo, para la igualdad efectiva de mujeres y hombres } \\
\hline 27.05 .2007 & 10 & 40,00 & 15 & 25 \\
\hline 22.05 .2011 & 10 & 40,00 & 15 & 25 \\
\hline 24.05 .2015 & 10 & 40,00 & 15 & 25 \\
\hline 26.05 .2019 & 10 & 40,00 & 15 & 25 \\
\hline
\end{tabular}

Número de mujeres y hombres por GGPP tras las elecciones del 26 de mayo de 2019:

\begin{tabular}{|l|c|c|c|}
\hline \multicolumn{1}{|c|}{ Grupo Parlamentario } & № de mujeres & № de hombres & Total Grupo \\
\hline GP Popular & 5 & 5 & 10 \\
\hline GP Coalición por Melilla (CPM) & 3 & 5 & 8 \\
\hline GP Socialista & 2 & 2 & 4 \\
\hline GP Mixto (VOX) & 0 & 1 & 1 \\
\hline GP Mixto (Ciudadanos) & 0 & 1 & 1 \\
\hline
\end{tabular}

